\title{
GADIR/GADES, CHARNIERE ENTRE DEUX MONDES: DYNAMIQUES DU COMMERCE MARITIME GADITAIN ENTRE LATLANTIQUE ET LA MEDITERRANEE (IV-I S. AV. J.-C.)
}

\author{
GADIR/GADES, HINGE AMONG TWO WORLDS: MARITIME TRADE DYNAMICS BETWEEN \\ THE ATLANTIC AND THE MEDITERRANEAN (4TH-1ST C. BC)
}

\author{
Max LUACES $^{1 *}$ y Antonio M. SAEZ ROMERO ${ }^{2 * *}$
}

${ }^{1}$ Universidad de Sevilla, Departamento de Prehistoria y Arqueología, Facultad de Geografía e Historia,
Calle Doña María de Padilla s/n 41004, Sevilla; Investigador post-doctoral Proyecto GREPURE
${ }^{2}$ Facultad de Geografía e Historia, Calle Doña María de Padilla s/n 41004, Sevilla
${ }^{*}$ Correo electrónico: mluaces@us.es
${ }^{* *}$ Correo electrónico: asaez1@us.es

Resumen: Durante los siglos IV y III a.C. la ciudad de Gadir experimentó una fase de transición desde un modelo económico expansivo y floreciente hacia otro más regional, limitado y "de vocación atlántica", que obligó a reorientar a las élites locales sus alianzas, su modo de vida y su papel frente a Cartago y sus aliados, y a otras ciudades del sur de Iberia y del ámbito del Estrecho. Sin embargo, las fuentes literarias del período tardorrepublicano subrayan la prosperidad de la ciudad de la época. Gades se presentaba, en efecto, como uno de los puertos más importante de esa época, gracias a la actividad de su rica élite de comerciantes y armadores en particular. En las dos últimas décadas nuevos descubrimientos arqueológicos han permitido caracterizar y entender cómo la ciudad púnica (y sus estructuras económicas) transitaron hacia la de nuevo floreciente bahía tardorrepublicana, que fue capaz de albergar algunas de las mayores fortunas del período augusteo. Nuestra contribución tiene como objetivo ofrecer una reflexión panorámica y una actualización de la interpretación del papel de la bahía gaditana como intermediario imprescindible en el diálogo económico y cultural establecido entre el mundo mediterráneo y la región atlántica entre el final del periodo púnico y la fase tardorrepublicana. Centrándonos en diversos casos de estudio y en el examen de las dinámicas del comercio marítimo, analizamos cómo la posición geoestratégica de la ciudad, en un punto bisagra entre dos dominios marítimos y dos continentes, fue determinante para consolidar su papel de potencia regional entre los siglos IV-III a.C. y cómo se hizo aún más importante en el contexto de la expansión romana, un proceso que las antiguas élites fenicias supieron canalizar y aprovechar en su beneficio.

Palabras Clave: Gadir, Gades, Cartago, Roma, economía antigua, romanización, ánforas.

\begin{abstract}
During the 4th and 3rd centuries BC the city of Gadir underwent a time of transition from an expansive and flourishing economic model to a more regional, limited and "Atlantic-oriented" one, which forced the local elites to reorganize their alliances, their lifestyle and their role facing Carthage and its allies, and other cities in the south of Iberia and in the Straits of Gibraltar area. However, the literary sources of the late Republican period emphasize the prosperity of the city at that time. Gades was indeed one of the most important ports of that period, in particular due to the activity of its wealthy elite of merchants and ship-owners. In the last two decades new archaeological discoveries have allowed a better understanding of how the Punic city (and its economic structures) transited towards the once again flourishing late-Republican bay, which was able to produce some of the greatest fortunes of the Augustan period. Our contribution aims to offer a panoramic view and an update of the interpretation of the role of the Bay of Cadiz as an essential intermediary in the economic and cultural dialogue established between the Mediterranean world and the Atlantic region between the late Punic and late Republican periods. Focusing on various case studies and the examination of the maritime trade dynamics, the paper analyses how the geostrategic position of the city, at a crossroad between two maritime realms and two continents, was decisive in consolidating its role as a regional power between the 4th and 3rd centuries B.C. and how it became even more important in the context of the Roman expansion, a process
\end{abstract}


that the ancient Phoenician elites were able to guide and exploit to their advantage.

Keywords: Gadir, Gades, Carthage, Rome, Ancient economies, Romanization, amphorae.

Sumario: 1. Introduction et objectifs. 2. La situation économique de Gadir au cours du IVème et du III ${ }^{\text {ème }}$ siècle av. J.-C. 3. Le début de l'époque romaine (vers 206-150 av. J.-C.): entre continuité et rupture. 4. La première expansion du commerce gaditain durant l'époque républicaine (vers 150-80 av. J.-C.). 5. L’apogée du commerce républicain de Gadir (vers. 80-40 av. J.-C.). 6. Conclusions. 7. Bibliographie.

\section{Introduction et objectifs}

Les sources littéraires et archéologiques actuellement disponibles semblent indiquer que le IVe siècle avant J.-C. a été une période de grands bouleversements dans l'espace méditerranéen, en raison de l'émergence de nouvelles puissances, autant à l'Est que dans sa zone centrale, et surtout en raison des affrontements diplomatiques, militaires et économiques que se sont livrés ces nouvelles puissances. Lors des périodes précédentes, ces changements dans l'équilibre des forces avaient eu un impact moindre sur les zones périphériques, en raison de leur déconnexion culturelle et de leur participation économique occasionnelle dans les circuits principaux. À l'inverse, dans la Méditerranée du IVe siècle, un espace alors de plus en plus monétisée, avec davantage de richesses en circulation, un poids plus important des marchés, ainsi qu'un réseau urbain consolidé et des sanctuaires côtiers, avec des usages communs en matière d'administration, d'habillement, d'alimentation et de consommation (et dans bien d'autres domaines), l'intégration accrue des périphéries a entrainé une interdépendance croissante et, par conséquent, une plus forte influence des grandes puissances et de leurs alliés sur les espaces périphériques. La projection de Carthage dans toutes les directions au cours de ce siècle, tant vers l'intérieur africain que vers l'Ouest et l’Est (Égée, Levant, Égypte) semble alors avoir été l'un des principaux facteurs ayant contribué à ces connexions "hellénistiques" et à la formation d'interdépendances économiques. Cette tendance à la "mondialisation" sera renforcée et multipliée au cours du IIIe siècle avant J.-C. avec l'expansion progressive de Rome et les affrontements avec Carthage, deux villes qui disposaient d'un grand nombre d'alliés et qui ont entraîné diverses communautés périphériques dans leurs conflits, que ce soit pour des besoins d'approvisionnement ou en raison d'enchevêtrements diplomatiques complexes.

Dans le cas de Gadir et de ce qu'on appelle le "Cercle du détroit", qui était au Ve siècle une ré- gion avec une projection extérieure notable et une personnalité culturelle et économique marquée, le IVe siècle avant J.-C. a entraîné un changement brutal dans les relations avec la reste de la Méditerranée. Cette région est en effet passée d'une phase de splendeur et de croissance, à une période de déclin et de régionalisation beaucoup plus importante. La région n'était pas entièrement coupée du monde méditerranéen, mais ses interactions possibles devaient passer par le filtre imposé par Carthage et ses alliés (au moins depuis le milieu du siècle). Malheureusement, ni les sources écrites, ni les découvertes épigraphiques, qui restent très rares au demeurant, ne fournissent un témoignage explicite, complet et de première main sur les évènements de cette période, et encore moins de précisions sur leurs conséquences du point de vue de l'économie (infrastructures, produits, itinéraires, accords commerciaux, etc.). En revanche, les sources archéologiques suggèrent qu'au moins à partir des années 375-350 avant J.-C. et jusqu'à l'arrivée des Carthaginois, sous la direction des Barca, les circuits économiques dans lesquels la cité de $G a$ dir était immergée ont été régionalisés, avec une projection alors destinée fondamentalement vers l'intérieur de la Péninsule et les espaces maritimes atlantiques. Il faut toutefois signaler que ces dynamiques se sont déroulées sans que la cité perde complétement sa connexion avec les modes, la demande et les réseaux d'échanges méditerranéens. Néanmoins, la richesse en circulation et accumulée dans la ville et ses sanctuaires, ainsi que sa capacité d'influence, semblent avoir souffert des nouvelles dynamiques en cours durant le IVe siècle, même si certains éléments au fondement de la puissance économique de la cité lors de la phase précédente (comme la production de salaisons) ont continué à représenter des activités de premier ordre, la redistribution de produits tiers a dû s'imposer comme une activité de plus en plus importante. Cette tendance a été soudainement et substantiellement modifiée par deux épisodes exogènes: l'occupation barcide et la seconde gue- 
rre punique, d'une part, et l'annexion ultérieure par la République romaine d'autre part, deux évènements qui mirent dans les deux cas définitivement fin à l'autonomie de la ville, d'un point de vue politique et économique.

Strabon nous offre une description de Gadir à la fin du premier siècle avant J.-C., dans laquelle ses sources l'amènent à indiquer qu'il s'agissait de la cité qui "rassemble la plus grande flotte marchande et les plus grands navires tant dans notre mer que dans la mer extérieure" (Strabo, Geog., III, 5, 3). L'auteur souligne également la prospérité de l'ancienne Gades, un fait qui s'étend également à toute la région environnante. Cette insistance sur la richesse des villes du sud de l'Hispanie, une région que Strabon appelle la Turdétanie, a longtemps été l'objet de doutes et de remises en question par la recherche historique, surtout lorsque ces phénomènes étaient abordés à partir des sources littéraires indiquant la conquête et l'assimilation romaine de la région, un processus qui avait débuté à la fin du IIIe siècle avant J.-C. à la suite des affrontements liés à la Seconde Guerre Punique (218-202 avant J.-C.) (Des Boscs-Plateaux, 1994: 12; 2005: 41-46).

Contrairement aux descriptions positives de Strabon sur la prospérité de la ville et de ses activités maritimes, et aux informations qui présentaient certaines de ses familles éminentes comme exemples d'enrichissement et de progrès social résultant de la "romanisation" des élites phéniciennes, les données archéologiques étaient insaisissables et peu concises en ce qui concerne l'évolution de la ville et de son infrastructure économique au début de l'époque républicaine. Comme mentionné ci-dessus, la plupart des données fournies depuis les années 80 du XXe siècle par les fouilles ou les relevés terrestres et sous-marins étaient liées à la puissance économique et commerciale de Gadir à l'époque classique, ou à celle de la fin de la période républicaine, entre l'époque augustéenne et le "Haut Empire". Les faiblesses de la documentation, ainsi que le manque de données archéologiques par rapport à la Gadir de l'époque archaïque, ont parfois été interprétées comme une conséquence ou plutôt comme le reflet déformé d'un récit empli de clichés et d'exagérations; un récit élaboré par un Strabon qui aurait cherché à légitimer la présence romaine, et aurait également été contaminé par la propagande promue par les élites urbaines elles-mêmes sur l'ancienneté de la ville et sur son rôle historique dans la région (Cruz, 1994: 84-85).
Cependant, au cours des dernières années, la multiplication des analyses qualitatives et quantitatives et le développement des études spécifiques, notamment en ce qui concerne la dimension économique et maritime de la ville, a permis de dissiper les doutes sur le tableau dressé par Strabon et sur le rôle tenu par Gades, en tant que clé de voute du réseau maritime et portuaire de l'Ouest romain, entre le IIe et le Ier siècle avant J.-C.

En premier lieu, l'étude de nombreux contextes productifs situés dans l'actuel district municipal de San Fernando (travaux dont la personne honorée dans ce volume a été l'un des principaux promoteurs) a progressivement fourni de nouveaux contextes qui ont démontré que le passage de la ville dans l'orbite romaine n'avait pas entraîné un démantèlement généralisé des infrastructures artisanales, ni de ruptures significatives dans la production d'amphores (synthèse dans Sáez, 2008). Les données fournies par des sites d'ateliers tels que Torre Alta, Luis Milena et Pery Junquera, notamment, sont éloquentes à cet égard, autant en ce qui concerne les structures de production qu'au regard de la caractérisation du mobilier céramique (Bernal et al., 2011; Carretero, 2004; González et al., 2002; Sáez et al., 2016). D’autre part, le renouvellement des données typologiques relatives aux amphores de Cadix a permis de mettre en évidence la longue continuité de la tradition morphologique locale (sans que cela entraîne une stabilité en ce qui concerne les volumes de ces conteneurs) tout au long de la période républicaine (Sáez, 2008). Les conteneurs commerciaux du début de l'ère romaine (les amphores dites "tardo-puniques") ont fait l'objet d'une attention croissante ces dernières années, ce qui a permis de préciser leurs évolutions typologiques et leurs relations avec d'autres éléments connexes, tels que les évolutions du timbrage, un champ d'étude qui a fait l'objet de nouvelles recherches récemment (Sáez et Ferrer, 2018). Bien que d'autres éléments non conservés, ou difficiles à identifier à partir du registre archéologique, aient dû jouer un rôle important (tissus de luxe, ivoires ou boiseries, esclaves, métaux en vrac, etc.), l'analyse des données matérielles à disposition confirme que la phase postérieure à la conquête romaine a représenté une période marquée par une augmentation significative de la production locale d'amphores, tout particulièrement entre le deuxième et le premier siècle avant J.-C., une dynamique qui impliquait des secteur de l'espace insulaire gaditain qui ne participaient pas 
jusqu'alors à la fabrication de céramiques (Sáez, 2010). Le dynamisme commercial de Cadix au début de l'époque romaine est également illustré par la très large diffusion de ces amphores tardo-puniques, lesquelles étaient à nouveau exportées vers l'Atlantique (entre la Galice et le sud du Maroc) (Ferrer et al., 2019), ainsi que vers la mer d'Alboran et sur tout le pourtour du littoral méditerranéen de la Péninsule, principalement entre Malaka et Tarraco (Pérez-Malumbres, 2012). Par ailleurs, la participation de ces conteneurs dans des réseaux d'échanges à longue distance est également attestée par les épaves et les contextes de consommation terrestres, les études réalisées dans le sud de la Gaule (Luaces, 2016) ou à Pompéi (Bernal et Sáez, 2019) étant particulièrement remarquables de ce point de vue. Ainsi, il semble que les IIe et Ier siècles avant J.-C. aient été une phase de grand essor économique pour Gades, phénomène qui a sensiblement modifié la structuration des circuits économiques de la cité établis lors de la période punique précédente.

Les dynamiques commerciales qui ont contribué à ce développement économique de la Gades romaine sont particulièrement complexes, et il est clair qu'il s'agissait d'un processus de longue durée. En outre, les preuves matérielles semblent montrer un lien entre l'expansion économique de l'époque républicaine et une influence italique de plus en plus marquée parmi les habitants de cette cité (García, 1996; Sáez et al., 2016), même lorsqu'elle était encore une cité fédérée, un constat qui ne concerne pas seulement le passage d'individus originaire d'Italia ou l'importation d'objets et de savoir-faire, mais aussi l'installation de colons et leur participation à des activités économiques clés (exploitation minière, préparation des denrées halieutiques, etc.). À cet égard, la documentation archéologique confirme l'affirmation de Strabon selon laquelle l'attachement des habitants de Cadix à Rome aurait été l'une des principales raisons qui expliquerait sa transformation en tant que principal relais régional de la puissance romaine (Strabo, Geog., III, 1, 8). Les deux phénomènes, l'expansion commerciale et le renforcement de l'influence socioculturelle exercée par l'Urbs, semblent s'être déroulés de manière conjointe. Notre objectif n'est pas ici de tenter de démêler les interrelations entre ces deux phénomènes, car ces questions ont été traitées dans des publications antérieures (García, 2019b; Luaces, 2019), et pas seulement pour le cas de Cadix (Le Roux, 2004; Gregoratti, 2015; Roman,
2009). Cependant, ce lien explicite entre l'économie et les évolutions socioculturelles nous amène à considérer le développement commercial de la Gades républicaine comme un phénomène progressif.

Les progrès importants réalisés par la recherche dans ce domaine ont permis d'identifier les étapes successives dans lesquelles s'est déroulée cette évolution et ce redéploiement de la projection commerciale de la ville républicaine (à nouveau internationale), par opposition à la rétraction de la fin de l'époque punique (avec ses circuits régionalisés) et à l'essor occasionnel du contexte barcide (également axé sur les marchés régionaux et l'approvisionnement de la "zone carthaginoi$\mathrm{se}^{\prime \prime}$ ). En effet, on peut identifier trois grandes phase pour l'époque républicaine: la première phase, datée entre 200 et 150 avant J.-C. environ, aurait été caractérisée par une continuité avec les phénomènes économiques de la période préromaine; une deuxième phase, datée entre 150 et 80 avant J.-C. environ, caractérisée par l'apparition de nouvelles formes de conteneurs et par une première extension des réseaux d'échanges gaditains en dehors de leur zone économique traditionnelle; une troisième phase, datée entre les années 80 et 40 av. J.-C., qui correspondrait à un moment de développement exponentiel du commerce de la cité, en lien avec un changement de statut administratif et une capacité de projection économique et culturelle probablement supérieure à la Gadir du Ve siècle av. (le temps de la "gaditanisation de l'Hispanie", Chic, 2004). Cette tendance générale a été caractérisée dans plusieurs études récentes, notamment par rapport au mobilier amphorique (García et al., 2019), mais ces approches n'ont pas été suffisamment associées aux transformations subies par l'urbanisme et la société de la Gadir punique avant qu'elle devienne la Gades romaine. C'est exactement ce que nous proposons de faire dans cette contribution, d'une part en rassemblant les principales données archéologiques relatives aux dynamiques économiques de la baie de Cadix entre le IVe-IIIe siècle avant J.-C. et le début de la période romaine, et d'autre part en examinant ces mêmes indicateurs pour la phase entre l'annexion et $\mathrm{Au}$ guste, dans le but d'établir une synthèse diachronique de l'évolution des dynamique commerciales de la ville au cours de ces périodes. L'objectif est de générer un outil accessible qui permettra de localiser historiquement les multiples témoignages écrits et archéologiques généralement analysés de manière isolée jusqu’à présent. 
2. La situation économique de Gadir au cours du IV ${ }^{\text {ème }}$ et du III ${ }^{\text {ème }}$ siècle av. J.-C.

La baie de Cadix, en tant que cité périphérique, située dans le cercle extérieur du "monde méditerranéen" du premier millénaire avant J.-C., a toujours été dépendante, d'un point de vue culturel et économique, des évolutions subies par les zones centrales de ce système, et surtout de l'influence exercée par les villes levantines (la métropole tyrienne en particulier), ainsi que celle liée à l'émergence du monde grec et à l'emprise de puissances comme Rome et Carthage. La périphérie atlantique, entre la colonisation phénicienne et l'expansion d'Auguste et de la Rome du Haut-Empire en Hispanie et en Maurétanie, a donc connu des moments de plus ou moins grande vitalité et autonomie, mais en termes généraux, elle a toujours été un secteur à la démographie, à la production et à la capacité d'influence très limitées dans le cadre général de la Méditerranée.

Pendant la période archaïque, au moins jusqu'au milieu ou à la fin du VIIe siècle avant J.-C., la baie de Cadix a dû être un espace avec un véritable poids politique, avec une économie encore à peine capable de se projeter même à l'échelle régionale, éclipsée par les colonies et autres centres névralgiques tels que Malaka. De fait, les communautés phéniciennes installées dans la région du détroit de Gibraltar étaient alors probablement tributaires et fortement dépendantes de leurs métropoles au Levant. La fin de ce siècle correspond vraisemblablement à un moment de transition vers un modèle urbain renforcé, avec une plus grande identité propre et une relative autonomie, bien que Gadir représentait encore une communauté secondaire dans le cadre régional (les Phéniciens d'Onoba et de Malaka, et leurs satellites, dirigeaient probablement les relations avec les "Tartessiens" et avec le monde grec), mais sans qu'il y ait de coupure brutale dans les relations avec Tyr et le Levant. Entre la fin du VIIe siècle et le milieu du VIe siècle, cependant, les infrastructures productives ont dû connaître un premier développement, en parallèle avec celui du rôle maritime et commercial de l'ancienne Cadix, comme le montre la prolifération des contextes funéraires avec de riches dépôts, avec des parallèles dans d'autres nécropoles puniques de Méditerranée centrale. Cette dynamique de croissance atteindra son apogée à partir de la fin du VIe siècle et pendant une grande partie du Ve siècle avant J.-C, ), par le biais d'un produit ina- ttendu (les salaisons de thons), et éventuellement par la combinaison d'autres facteurs externes, tels que l'irruption de nouvelles modes culinaires, l'existence de nouvelles ressources métalliques à utiliser pour l'acquisition de certains biens (marqueurs de statut) ou les difficultés (et opportunités) créées par l'expansion africaine et insulaire de Carthage.

Ce cycle de croissance économique et urbaine qui se manifeste archéologiquement dans des domaines tels que la nécropole de Cadix, la multiplication des infrastructures de production d'amphores ou la capacité à les faire parvenir à l'autre bout de la Méditerranée, ne s'est pas maintenue pendant plus de 3 ou 4 générations, avant de s'arrêter brutalement au moment où les marchés de l'Orient ont changé de priorités et où Carthage a placé ses efforts à l'Ouest et dans les mêmes ressources qui avaient soutenu l'expansion de Gadir (principalement les salaisons et les métaux). Comme cela a été souligné auparavant, les amphores de la baie ont disparu des marchés de l'Est et de la zone centrale de la Méditerranée à partir des années 400 avant J.-C. environ, et ont été systématiquement remplacées par des produits tunisiens et punico-siciliens, ce qui est un bon indicateur que l'économie de $G a$ dir a dû être réorientée vers la direction opposée (vers l'Atlantique), probablement dans le cadre d'une lutte continue avec Carthage, Ibiza et d'autres centres régionaux (Baria, Seks, Malaka, etc.), opposition qui se poursuivra jusqu'au débarquement d'Hamilcar à Gadir en 237 av. J.-C. L'issue des événements du dernier tiers du IIIe siècle avant J.C. est bien connue, et après avoir profité de la guerre pour s'insérer dans l'économie carthaginoise et bénéficier de ses circuits (alors alliés) et des besoins en approvisionnement induits par le conflit contre Rome, la cité de Gadir passa aux mains de Rome avec les mêmes intentions, probablement avec la conviction qu'il était désormais impossible de revenir à la situation antérieure d'indépendance et de relatif isolement régional ("Atlantisation"). Ainsi, dans les grandes lignes, on peut dire qu'entre 400 et 200 avant J.-C. environ, Gadir a été pris entre Carthage et Rome, et plus généralement a été rapidement rétrogradée à un statut secondaire en tant qu'axe d'un circuit économique régional (front atlantique ibéro-mauritanien et Turdétan) qui n'aurait été relié au reste des grands circuits méditerranéens que par l'intermédiaire de Carthage, d'Ibiza et ponctuellement d'autres acteurs échappant au contrôle de Gadir. 
Dans ce cadre, les différents marqueurs archéologiques disponibles peuvent aujourd'hui être analysés et interprétés d'une nouvelle manière. Comme nous l'avons déjà mentionné, ils renforcent généralement l'idée centrale selon laquelle Gadir a intelligemment joué un rôle de pivot entre deux mondes (la sphère atlantique et la Méditerranée), en se sauvant d'une situation économique et politique complexe et en contribuant de manière décisive à ce que la tradition phénicienne locale s'insère dans les dynamiques de la phase républicaine romaine. Parmi les preuves qui peuvent être analysées, la distribution des produits conditionnés en amphores est l'une des plus récurrentes dans la bibliographie, notamment en ce qui concerne l'exportation de salaisons, un argument valable et logique si l'on considère qu'il s'agit de marchandises fabriquées en grande quantité et avec de bonnes conditions de conservation. Sans vouloir surestimer son rôle, il ne fait aucun doute que les informations sur l'évolution des amphores locales et leurs cartes de distribution fournissent de précieux indices sur la capacité de projection et la progression de l'économie locale, comme cela a déjà été suggéré dans des travaux précédents (voir par exemple Sáez, 2018).

Entre le IVe et le IIIe siècle avant J.-C., les amphores gaditanes ont subi une transformation formelle aussi importante que l'infrastructure dans laquelle elles étaient fabriquées. Le groupe à succès des T-11210 a en effet été remplacé dès le début du IVe siècle par des formes qui ont évolué à partir de son schéma morphologique (T12111), lesquelles ont à leur tour donné naissance aux conteneurs T-12111/2 du dernier tiers du IIIe siècle avant J.-C. Tout au long du IVe siècle, les conteneurs du groupe T-8211 ont également pris de l'importance, évoluant à partir de versions locales de conteneurs ébusitains datés de la fin du Ve siècle avant J.-C. Ces conteneurs cylindriques, qui, comme les conteneurs dits de type Tiñosa issus des territoires proches, semblent répondre aux nouvelles tendances d'optimisation du style et du chargement des amphores puniques de l'époque. Il est probable que, parallèlement à ces dernières séries, d'autres conteneurs à fond plat dérivés du pithos classique ont également joué un certain rôle dans le commerce maritime, en tant que prédécesseurs directs des amphores T-9111, conteneurs dont les premiers profils avec un schéma similaire à celui du IIe siècle avant J.-C. (bien qu'avec une capacité beaucoup plus importante) semblent avoir été mis en place à partir du début du troisième siècle avant J.-C. Dans ce même contexte chronologique, à cheval entre deux siècles, apparaissent les premiers timbres, apparemment constitués de caractères anépigraphiques et avec des motifs très différents (Sáez et Ferrer, 2018). Ces timbres apparaissent alors en nombre limité, peut-être car ils étaient réalisés de manière occasionnelle à partir de bagues ou de pierres précieuses sculptées qui n'étaient pas conçues comme des instruments de marquage systématique.

La distribution de ces amphores locales, vraisemblablement liées à la fois aux conteneurs de poisson et de vin, a connu des bouleversements considérables au cours des IVe et IIIe siècles av. J.-C. (Figura 1): alors qu'au début de la période il semble que l'on atteigne encore des secteurs éloignés de la Méditerranée, comme Ampurias ou Ibiza, le tiers central de ce denier siècle semble marquer un déclin de la capacité de projection de ces conteneurs; dans le même temps, les navires et les amphores de Cadix atteignent les confins de l'Atlantique, au nord et au sud du détroit de Gibraltar, avec une certaine ponctualité au début mais avec une intensité beaucoup plus forte à mesure que l'implication dans les circuits méditerranéens se réduit. Une image paradigmatique de cette fluctuation, que nous avons appelée "l'Atlantisation" des réseaux d'échanges de Cadix (Sáez, 2018), concerne les établissements phéniciens ou ceux créés ex novo sur la côte sud du Portugal et le littoral de Huelva, où les énormes volumes de mobiliers de Cadix présents au cours des années 350-250 avant J.-C., ont conduit à parler d'une "gaditanisation" de la région (Arruda et al., 2013; Ferrer, 2004; Sousa 2020; Sousa et Arruda, 2010). Si nous examinons la documentation disponible pour la rive opposée de la région, les archives de Lixus, Zilil, Thamusida, Banasa ou Kouass suggèrent un succès similaire pour les marchandises de Gadir. Dans les deux cas il est possible que non seulement il s'agisse du résultat du rôle commercial prédominant joué par cette cité, mais dans certains cas il pourrait s'agir de fondations ou de refondations liées à la circulation des Gaditains eux-mêmes, celles auxquelles il a peut-être été fait allusion lors du périple d'Hannon et qui ont été attribuées aux Carthaginois. Cette tendance générale, peu projetée au-delà de la mer d'Alboran ou du sud-est au sens large, parallèlement à une intensification de la distribution et de la redistri- bution du côté atlantique, semble donner le ton au moins pour les amphores locales (et leurs vernis, vaisselle 


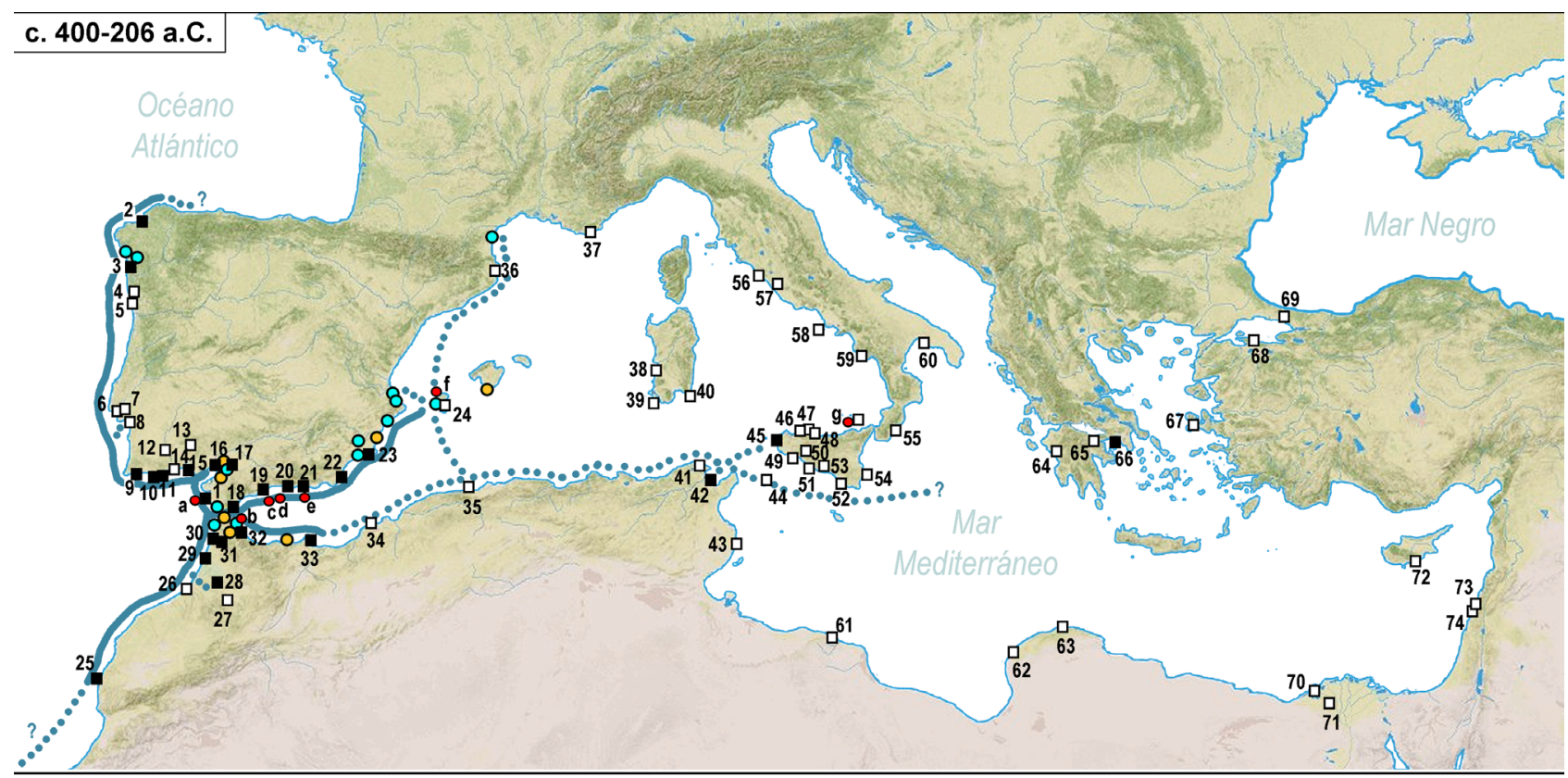

1) Baie de Cadix; 2) Baie de La Coruña; 3) Rías Baixas; 4) Castro de Coto da Pena; 5) Santa Olaia; 6) Lisbonne; 7) Almaraz;

8) Abul - Alcácer do Sal; 9) Monte Moliao; 10) Faro; 11) Tavira; 12) Mértola; 13) El Castañuelo; 14) Castro Marim; 15) Huelva;

16) Cerro Macareno; 17) Carmona; 18) Cerro del Prado - Carteia; 19) Malaga; 20) Almuñécar; 21) Adra; 22) Villaricos;

23) Cartaghène; 24) Ibiza; 25) Mogador; 26) Thamusida; 27) Rirha; 28) Banasa; 29) Lixus; 30) Kuass; 31) Zilil; 32) Vallée de Tetouan;

33) Melilla; 34) Les Andalouses; 35) lol-Caesarea; 36) Ampurias; 37) Marseille; 38) Tharros; 39) Sant'Antioco; 40) Nora; 41) Uttique;

42) Carthage; 43) Hadrumetum; 44) Pantelleria; 45) Mozia; 46) Palermo; 47) Solunto; 48) Himera; 49) Selinunte; 50) Entella;

51) Agrigente; 52) Camarina; 53) Monte Saraceno; 54) Siracusa; 55) Caulonia; 56) Pyrgi; 57) Roma; 58) Ischia; 59) Velia;

60) Tarente; 61) Lepcis Magna; 62) Euesperides - Berenike; 63) Cirene; 64) Olympie; 65) Corinthe; 66) Athènes; 67) Chios;

68) Cizique; 69) Byzance; 70) Alexandrie; 71) Naucratis; 72) Kition; 73) Sidon; 74) Tyr.

a) abords maritime de Cadix; b) littoral de Ceuta; c) épaves de Estepona et de Mezquitilla; d) Cueva del Jarro; e) littoral d'Adra; f) épave deTagomago $1 ; \mathrm{g})$ littoral des îles Eolias.

Figura 1. Synthèse des routes commerciales fréquentées par les marchands de Cadix pendant la phase d'“Atlantisation", aux IVe et IIIe siècles avant J.-C., dans laquelle sont indiqués les sites les plus pertinents par rapport à la diffusion terrestre et maritime des amphores gaditanes. Les cercles rouges indiquent

l'emplacement des épaves et des amphores isolées provenant de contextes sous-marins (a-g). Les points indiquent l'emplacement des amphores du groupe T-12111 (orange) et T-8211 (bleu clair). Les voies maritimes proposées reflètent les différents itinéraires possibles, entre les secteurs marqués par des

échanges réguliers (ligne continue), les zones occasionnelles de contact et celles associés à une éventuelle redistribution plus lointaine (ligne en pointillée) (composition à partir de Sáez, 2018: 20, fig. 3).

commune ou de cuisine, unguentaria, etc.) jusqu'à ce qu'elle se rattache à la phase archaïque, lorsque d'autres marchés méditerranéens et four- nitures militaires ont été rouverts.

La composition du commerce dans ces phases et les réseaux maritimes illustre également l'évolution exposée, ou du moins c'est ce que nous déduisons de ce qui a été publié jusqu'à présent (comme cela a été dit à propos du cas portugais; Sousa, 2020); chacune des zones qui constituaient le versant atlantique, presque monopolisé par $\mathrm{Ga}$ $d i r$, avait une demande spécifique qui était également satisfaite avec un ensemble spécifique de produits. Les commerçants de Cadix ont canalisé ces demandes spécifiques à travers leur port, en redistribuant et en incorporant de manière sélective leurs propres produits céramiques ou alimentaires dans cet approvisionnement. Une étude de cas qui illustre de manière paradigmatique ce scénario est celle de l'exportation d'amphores, qui auraient principalement transporté de l'huile, du vin et d'autres dérivés alimentaires, qui ont été distribuées par le biais des T-8211 et T-12110 de manière inégale vers les différents secteurs de la zone atlantique (García, 2019a; Sousa et Arruda, 2010: 957-960) et aussi avec une certaine intensité vers les noyaux de la côte atlantique de la Maurétanie, surtout au IIIe siècle avant J.-C. C. (divers 
exemples dans Aranegui, 2001, 2004; Arharbi et Lenoir, 2016; Kbiri, 2007).

Parmi les produits redistribués dans ces circuits figureraient, par exemple, des perles et des petites coupes en pâte de verre utilisées pour contenir des substances parfumées, des pierres précieuses et des pointes sculptées, et d'autres éléments qui, en raison de leur difficile conservation dans les registres archéologiques, sont actuellement invisibles. La céramique grecque du IVe siècle, peut-être comme au siècle précédent, aurait été un autre débouché essentiel de ce commerce de redistribution, reliant peut-être à travers Gadir les réseaux de redistribution puniques de la Méditerranée centrale et d'Ibiza à l'Extrême Occident du littoral atlantique. Il semble probable que tant les amphores (principalement pour le vin), que les objets à vernis noir ou à figures rouges documentés sur la façade atlantique aient trouvé un point de départ dans leur circulation à Gadir, point de rencontre préalable à leur distribution sélective en fonction de la demande de chacun des "marchés" représentés par chaque sous-zone incluse dans sa sphère économique. En général, il ne semble pas que pendant les deux premiers tiers du IVe siècle avant J.C., on puisse parler d'une grande intensité dans la consommation et l'utilisation de ces éléments dans l'une de ces sous-régions, loin du modèle montré par le monde ibérique méditerranéen, bien qu'il semble que leur possession ait également dû être un marqueur de statut associé à des situations et des pratiques spécifiques, apparaissant dans des environnements résidentiels, culturels ou funéraires. Alors que dans la baie de Cadix elle-même, son apparition fréquente dans les installations de fabrication suggère une "normalisation méditerranéenne" de leur utilisation et de leur consommation (tant pour les emballages de transport que pour la vaisselle; Cf. Bernal et al., 2013; Muñoz, 1997; Niveau et Vallejo, 2000; Sáez et al., 2020), dans d'autres parties de la zone atlantique, leur arrivée en quantités limitées (et aussi avec des formes et des origines répétitives) suggère une utilisation moins quotidienne dans de nombreux cas. Les données concernant les régions du nord-ouest et du centre-nord du Portugal (Ferreira, 2020; Gomes, 2017) indiquent une situation radicalement différente de celle observée pour l'Algarve (Arruda et al., 2019), le Guadiana (Mértola: Arruda et al., 1998), l'Estrémadure (Jiménez, 2017; Celestino et al., 2017), Huelva (Rufete, 2002) ou le Bas Guadalquivir (Cabrera, 1997; Pellicer et al., 1983), où leur consommation semble plus courante et régulière. Il en va de même pour les établissements de la côte atlantique de l'ouest de la Maurétanie, puisque les registres de Lixus, Kouass, Tanger et d'autres sites côtiers ou ceux situés en relation avec les grandes autoroutes fluviales permettent de déduire que la consommation est similaire à celle du sud de la péninsule (Kbiri, 2007: 161-168, note 9). Ce qui est le plus frappant, c'est que tant les amphores que les céramiques vernissées répètent presque systématiquement dans toutes les régions le même schéma de formes prépondérantes et d'ateliers de fabrication (ce qui est observable à partir de l'analyse des styles décoratifs de la figure rouge), ce qui suggère que l'offre était conditionnée par des voies d'accès très spécifiques pour ces produits, et que la demande pouvait donc également être conditionnée par la disponibilité dans l'Atlantique d'un répertoire limité.

À partir du dernier tiers ou quart du IVe siècle, et avec une intensité particulière à partir du début du IIIe siècle avant J.-C. (coïncidant avec des changements dans la typologie des amphores, l'apparition des sceaux, des menthes locales, etc.), l'impossibilité de maintenir ces importations a entraîné une résurgence de la production locale de la vaisselle vernie (dite "type Kuass"), et les productions de verreries ont donc largement comblé le vide laissé par les produits alimentaires. Dans le cas des amphores, l'apparition d'amphores corinthiennes, samiennes, de Chios et Grande Grèce (ou du moins leur arrivée très occasionnelle) a pu favoriser la présence croissante, mentionnée plus haut, de vin et d'huile produits dans presque toutes les sous-zones de Turdétanie (Pellicer D) ou dans la campagne de Cadix-Jerez de la Frontera (type Tiñosa). La distribution sélective semble s'être poursuivie dans cet espace atlantique, puisque sa consommation massive en Algarve-Huelva (Sousa, 2009), dans le Bas Guadalquivir (Escacena et Moreno, 2014) ou dans la zone maurétanienne ne semble pas trouver de correspondance dans une arrivée plus ponctuelle dans le Tage ou le nordouest de la péninsule ibérique (Sousa, 2020). La vaisselle gaditaine a rapidement été déclinée dans certaines de ces régions (comme le Bas Guadalquivir ou la région mauritanienne; Cf. Kbiri, 2007; Moreno, 2016), bien qu'il semble que ce soient les poteries de la baie qui aient largement bénéficié de l'opportunité laissée par la crise de l'exportation des produits agroalimentaires. Il n'a toutefois pas été possible de reproduire la production de 
cratères, de boulettes, de tasses et d'autres formes à figure rouge qui avaient été consommées par ces communautés du sud-ouest et de l'Atlantique, mais il a été possible de fabriquer des substituts formels avec des décorations de "style punique" qui pouvaient au moins permettre une fonctionnalité similaire.

Ce sont précisément ces "substituts" qui représentent l'une des études de cas les plus frappantes concernant ces connexions à l'intérieur des circuits commerciaux maritimes atlantiques qui traversaient la baie de Cadix (Figura 2). Ils illustrent à la fois la complexité de la lecture de ces circuits de redistribution, ainsi que le rôle que nous attribuons à Gadir en tant que nœud de connexion des systèmes ou circuits micro-régionaux qui constituaient son espace économique privilégié. Il s'agit de la distribution de formes de taille moyenne, qui auraient pu être utilisées pour le transport, mais qui ont surtout dû être exigées comme substituts des cratères et autres formes de mélange du vin. Il s'agit de formes que l'on rapproche généralement des "cratères", en correspondance avec les Pithoi de la fin de l'époque archaïque, lesquels semblent imiter la forme des cratères à colonnettes grecs. Leur apparition est relativement fréquente dans les contextes atlantiques mauritaniens, avec une présence particulièrement notable à Kouass (Ponsich, 1968: 21-22, lms. XVI et XX; Kbiri, 2007: 124133, forme A.V.5; Bridoux et al., 2015: fig. 3), où une production locale a été proposée; son décor particulier, peint sur la partie supérieure du corps, le cou et le bord, se rattache également aux produits attribués à l'atelier de Banasa (Girard, 1984: fig. 23), il semble donc probable que ce ne soit pas un, mais plusieurs de ces ateliers maurétaniens qui aient fabriqué des versions de ces "cratères à colonnettes". L'intérêt particulier de ces céramiques n'est pas tant basé sur leur forme ou leur inspiration des types grecs, ce qui suggère que la consommation de vin "à la grecque" était relativement fréquente dans leurs zones de production, mais plutôt sur l'identification récente d'un nombre notable de ces "cratéroformes" dans les voies fluviales galiciennes, au nord-ouest de l'Ibérie, en relation avec un horizon d'importations du IVe au IIIe siècle av. J.-C., qui comprend les amphores de Cadix T-8211 et T-12110, les céramiques "type Kouass" et des céramiques peintes également de Cadix, quelques pièces de stockage, des amphores Pellicer D et type Tiñosa turdétanes, et même une amphore de Grande Grèce MGS IV (Sáez et al.,
2020); en même temps, la découverte de ce type d'objets est quantitativement rare, peut-être parce que les gaditains avaient alors d'autres sources d'approvisionnement alternatives plus directes. Les données reflètent non seulement le renforcement probable d'une demande parmi les populations de la Galice actuelle, liée à la consommation de vin en lien avec les pratiques méditerranéennes, mais aussi la façon dont les expéditions pour satisfaire la demande spécifique de cette zone (stratégique en raison de l'accès à l'étain) ont dû être rassemblées dans le port de Gadir, en amalgamant des objets et des aliments d'origines très diverses: des vins grecs réputés, d'autres vins et huiles de Turdétanie, des salaisons et du vin local, des plats à engobe rouge de la région, des objets en pâte de verre (perles et amphorisques), des bouteilles en céramique avec des huiles parfumées, ainsi que les "cratéroformes" maurétaniens, sur lesquels il n'est pas possible de préciser s'ils transportaient un quelconque type de contenu ou si leur succès ne résidait que dans leur forme et leur utilisation à destination. L'image est complétée par des données supplémentaires sur le centre-sud du Portugal, le Bas-Guadiana, Huelva et le Bas-Guadalquivir, où ces "cratéroformes" n'ont pas été identifiés, malgré le fait que toutes ces zones aient reçu un impact massif des amphores de Cadix et de Turdetan, des céramiques du grenier et de "type Kuass", etc.

Cette synthèse des réseaux et des rythmes du commerce maritime à Gadir aux IVe et IIIe siècles avant J.-C., présentée dans les paragraphes précédents, aide de manière décisive à comprendre d'autres aspects liés à l'activité de cette cité, tels que le rôle du port de Gadir et de ses principaux sanctuaires comme base de voyages et d'expéditions vers l'Atlantique (López, 2008; Mederos, 2006, 2015; Mederos et Escribano, 2000, 2004, 2015), non seulement à des fins d'approvisionnement et de refuge, mais aussi comme point de collecte de données nautiques essentielles. La rareté des données sur les épaves pouvant être datées pendant cette période réduit les possibilités de localiser les routes et de caractériser la composition des cargaisons qui ont circulé dans le versant atlantique ou depuis/vers la Méditerranée, bien que les points les plus renseignés des épaves, des épaves possibles ou des mouillages (La Caleta, La Mezquitilla, Estepona, Cueva del Jarro, Ceuta, etc.) suggèrent une large circulation de cargaisons hybrides, dans lesquelles les amphores de Cadix se- 

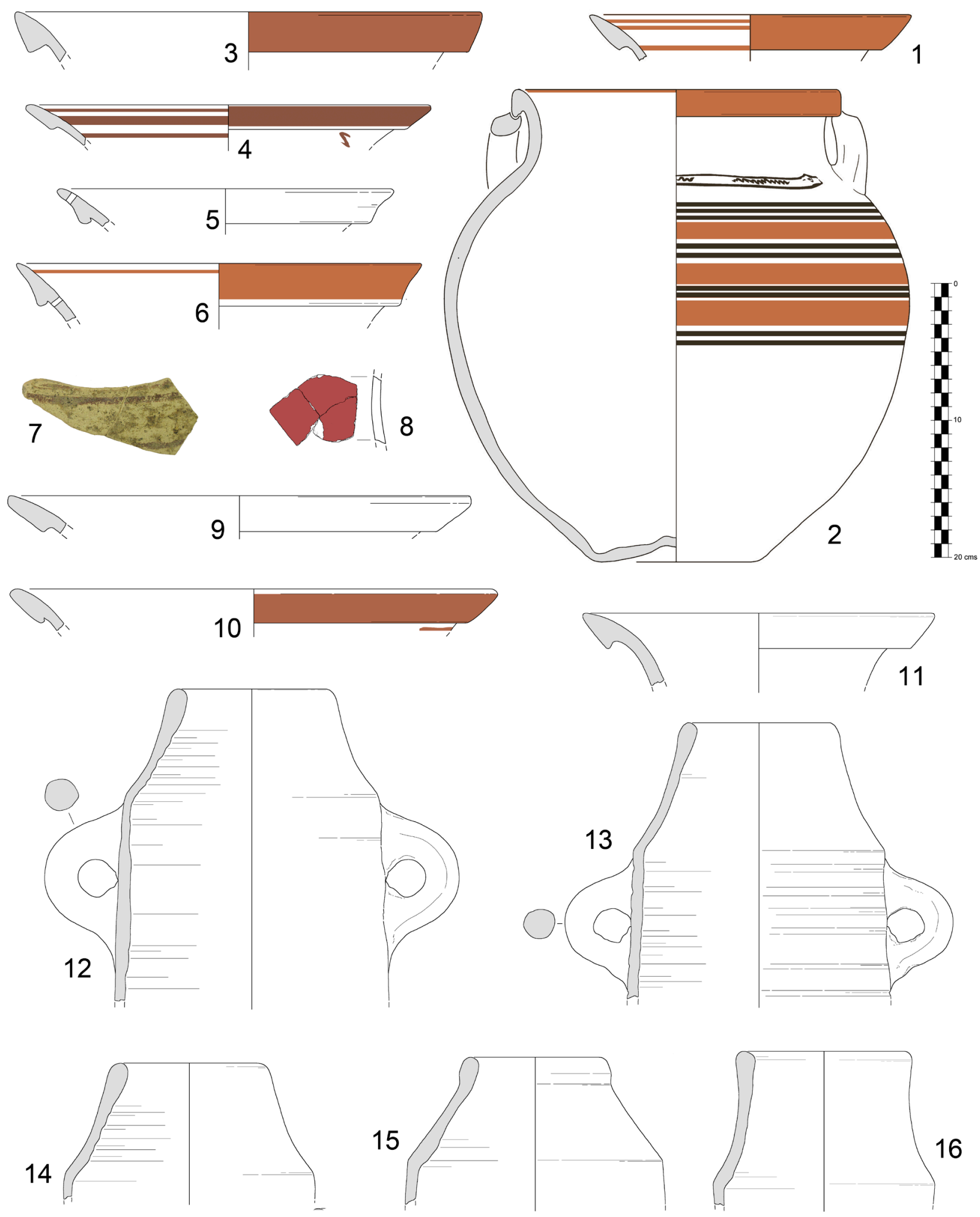

Figura 2. Céramiques qui illustrent les liaisons maritimes à l'intérieur du versant atlantique de la région du détroit, centralisées sur la cité de Gadir: jarres peintes "cratériformes" mise au jour à Kouass et probablement originaires de Maurétanie (1-2); jarres de typologie similaire récupérées dans les gisements de castreño d'A Lanzada, Neixón, Punta do Muiño et autres (3-10); jarres et amphores T-12111 datés des IV-III siècles a.C. découvertes dans des contextes de la baie de Cadix, probablement originaires de Maurétanie ou en provenance d'autres centres côtiers maurétaniens (Bridoux et al., 2015; Sáez et al., 2020). 
raient combinées en direction de la Méditerranée avec d'autres de production carthaginoise, malacitaine, etc. (sans que, malheureusement, nous ayons pour l'instant à notre disposition ne serait-ce qu'un seul exemple d'épave clairement liée aux réseaux purement atlantiques; Cf. Sáez, 2014).

Les informations publiées sur l'importation de marchandises destinées à une redistribution à des tiers (céramique grecque), et d'autres qui semblent plus orientées vers l'approvisionnement de la baie elle-même (sites punique de Méditerranée centrale et Ibiza, Levantin ibérique, etc.), suggèrent que Gadir a agi comme un filtre ou un tamis qui a contribué à diffuser les influences hellénistiques au sens large, et certaines modes culturelles et culinaires en particulier, en direction de l'Atlantique. Les céramiques attiques présentes dans l'archipel gaditain et sur le continent ne semblent pas très différentes des répertoires exportés dans les autres sous-régions de la sphère d'influence de la cité, avec une prédominance de tasses et de verres à boire en vernis noir par rapport aux pièces en FR, tandis que les amphores comprendraient surtout des exemples de vins originaire de Grande Grèce (MGS IV, "protogrecoitallic"), des récipients de type champignon à rebord, "samiens" ou de Thasos, et d'autres types populaires à l'époque. Seule une partie de ces importations n'a pas été consommée dans la baie elle-même, et elles ont plutôt participé aux réseaux de redistribution vers la Mauritanie, la façade ouest de l'Ibérie et le sud-ouest. Les produits carthaginois, siciliens et d'Ibiza sont tout aussi limités en nombre, bien qu'ils aient augmenté à partir de la fin du siècle, et correspondent principalement aux types amphoriques $\mathrm{T}-4215$ et $\mathrm{T}-5230, \mathrm{~T}-3212$ et $\mathrm{T}-8111 / 8121$, avec encore moins d'exemples de vaisselle vernie et d'autres articles (pierres précieuses, blocs de pâte de verre, etc.). Il est probable que, comme c'était le cas à la fin du Ve siècle avant J.-C., les amphores ibériques retrouvées régulièrement dans ce secteur, qui étaient fabriquées dans la région d'Alicante et/ou de Murcie, ainsi que les T-12111 et T-8211 provenant d'ateliers de la côte méditerranéenne de la région du détroit, voyageaient à travers des cargaisons hybrides constituées lors de diverses escales effectuées dans de nombreux cas à Ibiza (soit chez des marchands d'Ibiza, soit sur des navires de retour vers Cadix).

Les données archéologiques sur le commerce maritime semblent également trouver une correspondance historique significative dans la baie elle-même, soutenant l'existence de diverses phases avec différentes tendances économiques tout au long des IVe et IIIe siècles avant J.-C., en relation avec la géographie de la production, l'urbanisme et des aspects tels que les rituels et les dépôts matériels de la nécropole insulaire. L'évolution des infrastructures de production témoigne d'une première crise, en lien avec une intense restructuration, durant les premières décennies du IVe siècle, phénomène que l'on peut observer dans diverses fabriques à salaisons, comme dans les cas de Las Redes (Muñoz et al., 1988), Los Chinchorros (Sáez et Lavado, 2019) ou Puerto 19 (Sáez et al., 2020), ainsi que dans les ateliers qui produisent des amphores, comme Camposoto (Ramón et al., 2007) ou Villa Maruja (Bernal et al., 2003; Sáez et Belizón, 2018). Cependant, dans tous les cas, leur diffusion insulaire et continentale s'est poursuivie sans véritables changements et, dans la plupart des cas, une réactivation de l'activité a été observée dans les mêmes endroits peu après, avec une nouveau développement des infrastructures de production à partir du IIIe siècle avant J.-C. (comme cela est illustré par les ateliers de Torre Alta, de la Plaza de Asdrúbal et de nombreux autres cas dans l'espace insulaire et des environs de la zone portuaire). Cependant, l'orientation productive de ces établissements a alors changé, car dans de nombreux cas, ils sont passés de points ayant une fonctionnalité presque unique (production céramique ou fabrique à salaison) à des contextes de production ruraux multifonctionnels, qui ont probablement combiné de nouveaux apports techniques à ceux issus de la tradition locale (mortiers à base de chaux hydraulique, moulins rotatifs, fours circulaires à couloir allongé, etc). L'apparition en périphérie de la baie d'installations telles que le Cerro Naranja (apparemment pour la production d'huile) ou les presses des sites de Castillo de Doña Blanca et de Las Cumbres, témoignent clairement du changement d'orientation de l'économie, alors marquée par une diversification de la production agroalimentaire locale, en lien non seulement avec une baisse de la demande extérieure pour les salaisons, mais aussi à des changements dans le régime alimentaire et les habitudes culinaires au niveau local et au niveau de la zone d'influence économique des Gaditains.

En termes généraux, les infrastructures et les données indirectes offertes par les céramiques issues de contextes sous-marins autour de l'archipel pour cette période (Sáez et Higueras-Milena, 2016; 
Sáez et al., 2016) décrivent une courbe ascendante de l'activité économique locale et de sa capacité de projection régionale (atlantique), qui doit avoir atteint des niveaux élevés au milieu du IVe siècle et s'est accrue en intensité et en complexité tout au long du IIIe siècle avant J.-C, probablement pas en raison d'une confrontation avec Carthage et ses alliés mais plutôt du fait de l'intérêt offert par sa position de "périphérie nécessaire" (essentiellement pour l'accès aux gisements métalliques de la zone atlantique) dans laquelle Gadir a pu constituer une véritable zone d'influence (un "cercle du détroit" atlantique, avec la mer d'Alboran, en opposition avec les cités de Malaka, Seks ou Baria, scénario dans lequel Ibiza aurait également eu beaucoup à dire). L'évolution de la nécropole à partir de cette période est malheureusement aussi mal connue que la localisation et l'étendue du centre urbain de l'île et de ses infrastructures portuaires, ce qui rend difficile tout étude visant à établir un modèle à comparer avec les données offertes par les contextes de production. Les données générales publiées jusqu'à présent (Muñoz, 1997; 2008; Niveau de Villedary, 2009) suggèrent que cette "invisibilité" partielle pourrait être due précisément à un appauvrissement des tombes, des rituels et des dépôts funéraires, avec une perte de la monumentalité typique du Ve siècle avant J.-C., mais une répartition similaire dans tout le secteur au sud du possible centre urbain. L'inhumation semble continuer à régner, maintenant dans des tombes avec des couvertures en dalles ou en pierres de taille, avec des amphores ou sans couvertures, avec peu d'éléments métalliques (peu de bijoux en or, plus objets en bronze doré) et une présence croissante d'éléments céramiques, surtout dès le IIIe siècle avant J.-C., des vases globulaires avec des bandes rouges qui imitent clairement les prototypes carthaginois (Sáez et López, en prensa). Un scénario général qui souligne la connexion de la ville et de ses élites avec Carthage, Ibiza et la sphère culturelle hellénisée de la Méditerranée centrale, avec ses goûts et ses formules de transit vers l'au-delà, et qui pourrait être, surtout pour les sous-phases situées à partir du milieu du IVe siècle avant J.-C., le reflet de ce rôle subordonné et complémentaire du circuit atlantique mené par Gadir dans le réseau général des échanges commerciaux avec un centre à Carthage.

En guise de conclusion, nous pouvons dire, en résumant les données présentées tout au long de ce chapitre, que l'on peut observer entre les IVe et
IIIe siècles avant J.-C. plusieurs phases, intimement liées, dans l'évolution de l'économie, du commerce et de la projection commerciale de Gadir. Une première phase, que nous pouvons probablement situer dans la première moitié du IVe siècle, a représenté une étape de restructuration et de réorientation du modèle économique gaditain. Cette étape fut probablement difficile et a marqué un déclin vraisemblable de la cité, mais sans conduire à la disparition des infrastructures de production et sans modifier substantiellement le rôle des élites oligarchiques locale. Gadir serait alors devenu un acteur mineur dans les réseaux méditerranéens, cette faiblesse des gaditains étant rapidement comblée par Carthage et ses alliés. Une deuxième phase peut être située approximativement entre le milieu du IVe siècle avant J.-C. et le premier tiers du IIIe siècle avant J.-C., dans un contexte politico-diplomatique marqué par le traité romain-carthaginois signé en 348 avant J.-C., un texte qui traduit probablement l'apparition de circuits, de formules de contact et de sphères économiques plus restreintes que lors des phases précédentes. A ce stade, Gadir se montre à nouveau un acteur secondaire mais probablement déjà aligné sur les intérêt carthaginois, avec une reprise évidente de son activité et de ses infrastructures, et avec une production locale de vaisselle - rouge et grise - ce qui laisse penser que le passage au crible des modes hellénistiques à travers la Méditerranée centrale punique a dû modeler d'autres aspects qui, faute de sources écrites ou épigraphiques, nous échappent (structure administrative, fonctionnement des sanctuaires, etc.). Lémission de monnaies locales, qui aurait débuté à cette époque, ainsi que la datation des premiers timbres sur les amphores, sont deux autres témoignages extrêmement intéressants de cette "hellénisation" indirecte de la ville et de son économie, et du lien avec la Méditerranée, probablement au travers des contacts avec Ibiza et Carthage. Enfin, les deux derniers tiers du IIIe siècle avant J.-C., marqués par les guerres entre Carthage et Rome, placent Gadir et sa zone d'influence atlantique comme une périphérie utile aux intérêts carthaginois, d'abord comme centre d'approvisionnement (comme indiqué par l'augmentation des infrastructures et de la production de Cadix) et ensuite comme port et base stratégique dans son expansion péninsulaire et l'accès à des ressources stratégiques, telles que les métaux du quadrant nord-ouest de la péninsule. Rome reprendra en grande partie ce dernier schéma, en offrant aux gaditains un accès direct 
aux principaux circuits commerciaux méditerranéens de l'époque, comme l'avaient fait les Barca en leur temps.

\section{Le début de l'époque romaine (vers 206-150 av. J.-C.): entre continuité et rupture}

La fin de la deuxième guerre punique (218-202 av. J.-C.) a eu des conséquences importantes pour les riches cités du sud de la péninsule ibérique, en particulier pour les communautés du cercle du détroit. Contrairement à la plupart des villes de la région de Gibraltar, Gadir a réussi à sortir relativement indemne de ce conflit, grâce à la signature d'un foedus avec Rome en 206 avant J.-C. (López, 1991). L'épisode est bien connu et il n'est pas nécessaire d'entrer ici dans les détails de cet évènement historique. Il faut toutefois noter que les élites de Cadix ont été les initiatrices de ce traité avec les Romains, et que ce texte a marqué un tournant majeur dans leurs relations avec Rome. En tout cas, si la présence romaine semble parfois avoir été une source de tension pour les villes du sud de l'Ibérie, notamment pour celles issues de la colonisation phénicienne, la situation dans le cas de $\mathrm{Ga}$ dir était tout autre. En effet, la plupart des anciennes cités phéniciennes de la région de Gibraltar se sont soulevées contre Rome dès l'année 197 av. J.C. (López, 1995: 150-153), mais Gadir semble toutefois ne pas avoir participé à cette insurrection. Il $\mathrm{y}$ a des raisons de penser que la ville n'aurait pas eu subir une véritable ingérence extérieure ou des changements brutaux au début de la période romaine, d'autant plus qu'elle était devenue un allié stratégique pour Rome, un constat qui s'étendait également au cas des interactions économiques.

L'étude des contextes archéologiques semble confirmer cette continuité entre la fin de la période punique et le début de la phase romaine. Tout d'abord, différents sites archéologiques de la baie indiquent une persistance des activités productives entre les IIIe et IIe siècles avant J.-C. Cette continuité est par exemple visible dans la plupart des centres artisanaux de la baie de Cadix, qui ne présentent aucune trace d'abandon ou de discontinuité des infrastructures de production pendant les premières décennies de la domination romaine (González et al., 2002: 17-27; Sáez, 2010: 899-901; Sáez et al., 2016: 34-37). En outre, il existe une continuité évidente dans les différents répertoires matériels présentés par ces établissements productifs depuis le début de l'ère romaine: les formes des amphores ont continué à appartenir essentiellement à la tradition punique locale, tandis que les structures de production sont également liées à une référence locale antérieure, ce qui est illustré par l'utilisation de fours circulaires avec une colonne centrale (Sáez, 2011, 2013). De même, les données matérielles montrent la continuité de l'importance des activités liées à la commercialisation des produits de la pêche dans l'économie de Cadix, puisque les installations de production liées à cette "industrie" ont également continué à fonctionner au début de la période romaine. Cette continuité se retrouve également dans l'organisation des circuits commerciaux de la Gadir romaine. En fait, il semble que les produits de Cadix se soient surtout répandus au niveau régional entre 200 et 175 avant J.-C., la circulation étant toujours centrée sur la région du détroit de Gibraltar, tant du côté ibérique que maurétanien (Ramon, 2008). Les communautés atlantiques, autre marché traditionnel pour les produits de Cadix, ont également continué à s'approvisionner en amphores de poisson salé et en vin Gaditain (en fréquentant leurs bateaux des Casitérides à Mogador, au moins; Sáez et al., 2020). Il convient de noter qu'il existe peu de preuves jusqu'à présent de la propagation des produits de Cadix en Méditerranée occidentale entre 200 et 175 avant J.-C. environ, à l'exception de certains endroits traditionnellement associés aux réseaux commerciaux des villes du détroit, comme Malaka ou Ibiza (Pérez-Malumbres, 2012: 382383; Ramon, 2008: 84-86). Cette apparente continuité historique a des conséquences négatives par rapport à son analyse archéologique. Il est donc difficile d'établir une distinction claire entre les contextes des deux périodes (avant et après 206 avant J.-C.), et il n'existe pas encore d'appui solide d'un point de vue chronologique pour les contextes des premiers romains de Cadix. Dans cet état de fait, il est possible que certains contextes céramiques considérés comme antérieurs à la conquête romaine datent en fait du début du IIe siècle avant J.-C. et inversement.

Plusieurs questions doivent être examinées si nous voulons essayer de trouver des explications satisfaisantes pour cette première phase de continuité. Tout d'abord, il convient de noter que Rome n'a pas cherché à imposer son modèle culturel, contrairement à ce qui a parfois été suggéré (MacMullen, 2003: 193-194). L'État romain cherchait avant tout à s'assurer du contrôle des ressources et des personnes, un contrôle qui, pour être effi- 
cace, devait être exercé selon les modalités et les normes en vigueur dans l'Italie romaine (García, 2019b: 167-172; Ruiz, 2009: 225-228). Pour cette raison, les Romains ont dû réorganiser les territoires associées aux villes sous leur contrôle, soit par la centuriation des terres - c'est-à-dire la division du territoire conformément aux mesures romaines - soit par la distribution des parcelles destinées à enrichir l'ager publicus. Cette réorganisation a également touché certaines activités économiques, notamment la production minière et le développement agricole (Domergue, 2004: 223-226; Martín et al., 201: 206-218), car ces deux voies étaient des sources de ressources préférentielles pour faire face à l'impôt (stipendium) que les villes conquises devaient payer à l'État romain. Cependant, cette réorganisation des activités économiques n'a pas affecté Gadir, qui était alors une ville alliée à Rome et non une communauté stipendiaire. Cette certaine indépendance vis-à-vis des transformations induites par la conquête romaine pourrait expliquer le peu d'intérêt de ses dirigeants à participer à l'insurrection "libyo-phénicienne" de 197 avant J.-C. Ayant bénéficié de conditions avantageuses, les élites de Cadix auraient probablement préféré maintenir cette position, profitant de l'ambiance belliqueuse et des besoins croissants des troupes, des flottes et de l'approvisionnement des zones minières. Les tensions dans la région contre la domination romaine ont peut-être aussi conduit Rome à essayer de renforcer un soutien important dans le panorama régional, d'autant plus que Gadir représentait l'un des points d'accès essentiels pour la navigation au-delà des colonnes d'Hercule. Il faut rappeler que les routes maritimes représentaient à l'époque la principale voie d'accès vers la nouvelle province de l'Ulterior (Arnaud, 2019: 210-212), la route terrestre à travers le sud de la Gaule, alors indépendante n'était pas encore sécurisée au début du IIe siècle avant J.-C. La situation de Gadir, cité située à un point névralgique au carrefour des voies de communication maritimes entre l'Atlantique et la Méditerranée, a peut-être renforcé la politique favorable de Rome à son égard.

Malgré cette attitude accommodante, on constate que la sphère économique de Gadir a également été affectée par l'influence du mode de vie romain après la conquête, surtout dans le domaine des activités de production. Bien qu'elles aient été plutôt restreintes, les marques de l'influence romaine sont flagrantes dans la documentation archéologique des années 175/150 avant J.-C., période pendant laquelle on peut observer l'introduction de nouveaux éléments techniques dans les centres de production (types de fours, cocciopesto, etc.), avec des références dans l'Italie romaine (González et al., 2002: 17-27; Sáez et al., 2016). On observe également des changements dans la forme des conteneurs de transport, bien que les transformations aient été relativement limitées au départ, et qu'elles ne reflètent pas vraiment une modification profonde du point de vue du déroulement des activités de fabrication. Il convient toutefois de noter que les importations de céramiques italiques semblent avoir considérablement augmenté au cours de la même période. Divers éléments de la vaisselle à vernis noir "campanienne" avaient été importés à Gadir bien avant la conquête romaine, mais ces articles de vaisselle italiques semblent être plus fréquents dans les contextes datés des années 175/150 avant J.-C., en même temps qu'ils commencent à exercer une influence notable sur le répertoire céramique produit dans la baie de Cadix (Niveau de Villedary, 2004; Niveau et Sáez, 2016). En outre, la consommation locale de produits conditionnés dans des amphores italiques (essentiellement du vin) a également commencé à augmenter sensiblement au cours de cette période, alors que cette consommation était auparavant plutôt occasionnelle ou minoritaire (López et Sáez, 2020; Sáez et Higueras-Milena, en prensa; Sáez et al., 2016). En tout cas, les données archéologiques de Gadir/Gades suggèrent avant tout une relative continuité avec la phase préromaine, illustrée par l'utilisation des mêmes canaux de diffusion maritimes que lors la période précédente et par un niveau de productivité a priori comparable (García et Sáez, 2018), la plupart des ateliers, fabriques et d'autres infrastructures en activité lors des décennies antérieures étant encore actives durant le début de l'époque romaine (Figura 3).

Cependant, la présence romaine a commencé à se faire sentir rapidement, au moins au niveau de l'économie locale. Dans le cas de la production d'amphores, l'un des indicateurs archéologiques les plus visibles et les plus explicites, on peut observer certains changements qui révèlent ce changement de direction (Figura 4). D'une part, la production d'amphores de type gréco-italique semble être typologiquement cohérente avec l'évolution de leurs prototypes italiques, et quantitativement elles prennent une place de plus en plus importante au sein des répertoires de production des ateliers locaux. D'autre part, il semble que les sys- 


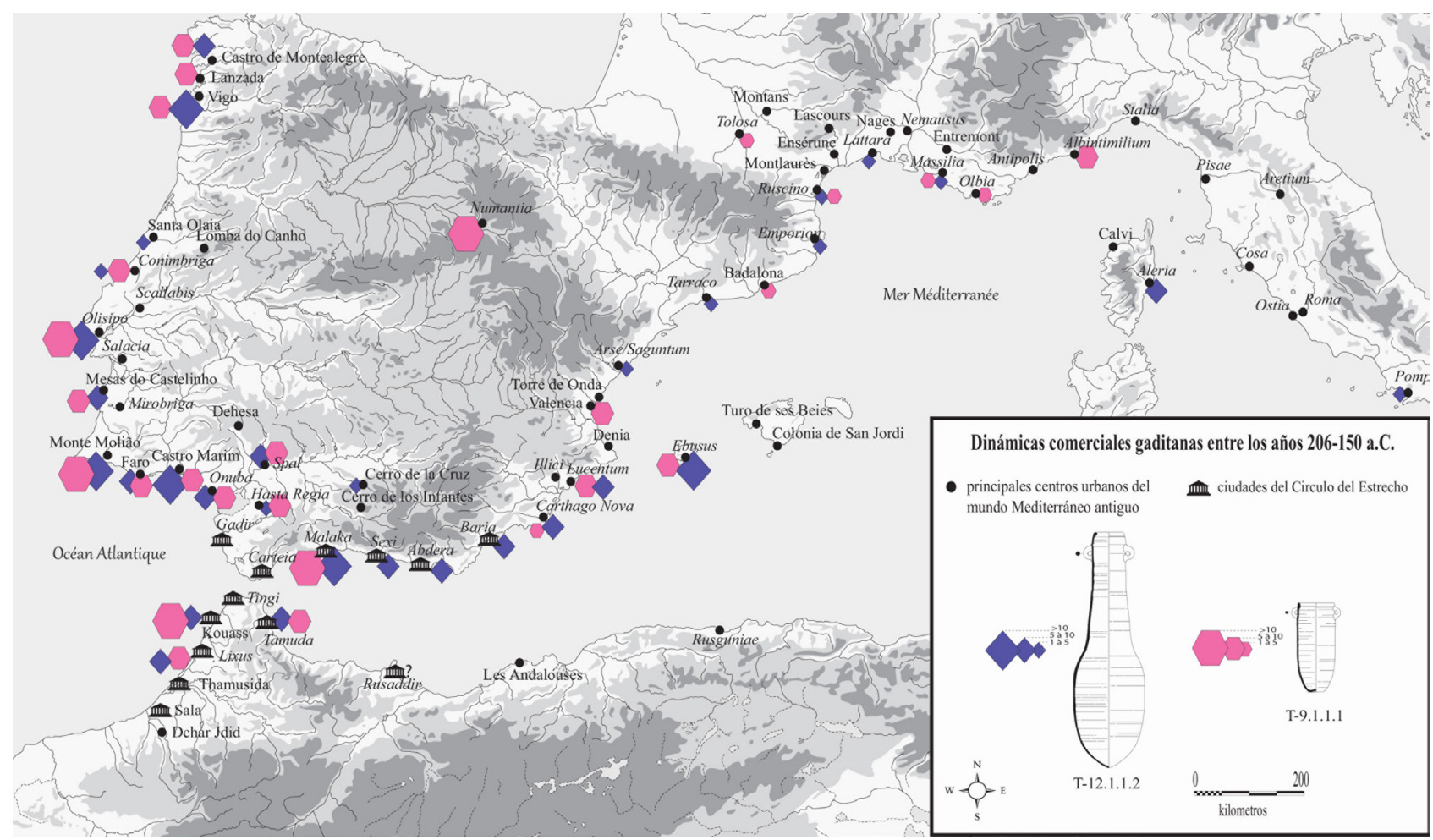

Figura 3. Carte de dispersion des types amphoriques tardo-puniques T-12112 et T-9111, deux types de conteneurs au cœur de l'appareil productif gaditain des années 206-150 av. J.-C. On note que la diffusion de ces mêmes conteneurs correspond en grande partie aux voies de circulation des produits gaditains observées pour les époques préromaines (voir la Figura 1).

tèmes d'estampage de la tradition locale (bagues signataires avec des chatons décorés, dont beaucoup avec des motifs faisant allusion à la pêche et aux conteneurs) aient disparu au profit d'artefacts moins soignés, bien que faisant allusion aux mêmes thèmes mais en incorporant d'autres probablement déjà sculptées sur le bois ou d'autres supports moins nobles. De même, les formes puniques traditionnelles (T-12112 et T-8211) perdent progressivement de leur importance au profit des formes tubulaires T-9111, lesquelles, avec leur morphologie différente et avec leur fond plat, semblent être la forme la plus demandée durant les décennies centrales de ce siècle. Dans ce contexte, on peut également observer des changements dans les normes de capacité des amphores, qui semblent réajuster leurs tailles et leurs profils pour s'adapter aux systèmes métriques liquides romains, laissant derrière elles la tradition syro-phénicienne précédente (Sáez et al., en prensa). Probablement aussi en relation avec cette adaptation aux motifs romains, il convient de noter l'apparition durant cette phase de la monnaie locale de la série VI d'Alfaro Asins (1988), qui bien que conservant en général les types et modèles traditionnels, montrent un nouvel accent romain dans leurs modules, et circulent tout au long du IIe siècle et une bonne partie du Ier siècle avant J.-C. dans un rayon beaucoup plus large, probablement en parallèle avec la phase d'essor qui suit cette première moitié de ce siècle de continuité.

Cette nouvelle tendance tout au moins entraîné une première extension des réseaux commerciaux de Cadix vers l'Italie romaine, réseaux qui, à l'époque, visaient principalement à recevoir des produits italiens et à les distribuer sur les marchés qui constituaient les circuits commerciaux de Cadix, au niveau régional et en direction du littoral atlantique. Les causes de ce renforcement de l'influence économique de l'Urbs en direction de la côte de l'Ulterior sont certainement liées à l'augmentation de la menace lusitanienne et à la préparation des campagnes militaires romaines qui se sont déroulées dans la région dans le quart de siècle suivant. En effet, le péril posé par les populations de la frange occidentale de la Péninsule est devenu de plus en plus menaçant au cours de la première moitié du IIe siècle avant J.-C. (Apia. Iber. 59-62). Face à cette menace croissante, le soutien militaire de Rome était une nécessité pour les riches centres urbains du sud de l'Ibérie (Berrocal-Rangel, 2017), tandis que les Romains avaient également 


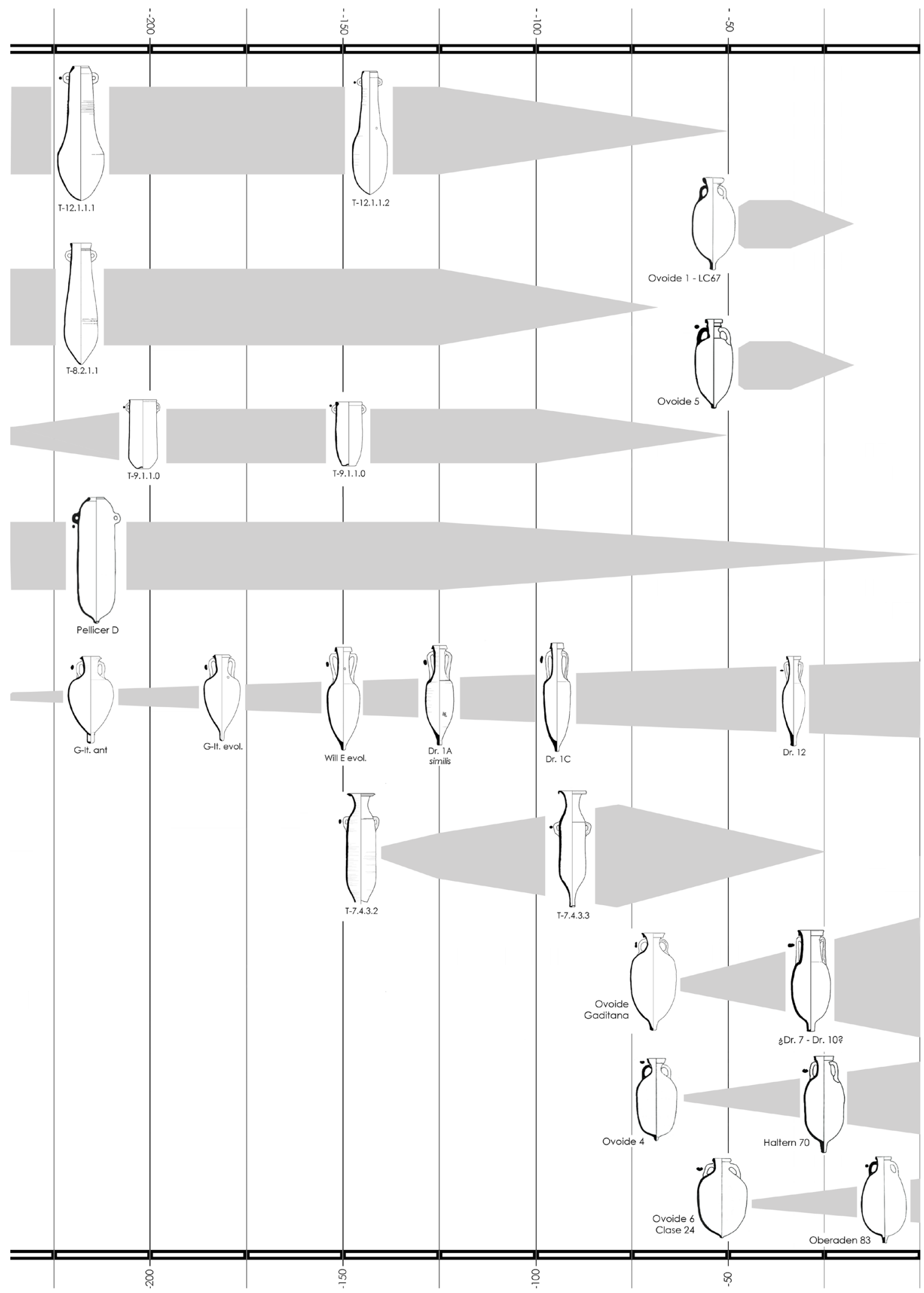

Figura 4. Principaux groupes d'amphores mentionnés dans le texte, impliqués directement ou par redistribution dans le commerce de Cadix entre le IIIe et le Ier siècles avant J.-C. (y compris les produits conditionnés en amphores provenant des vallées du Guadalquivir, du Guadalete, d'Iro et des environs de Cadix-Jerez de la Frontera). Les bandes grises indiquent, approximativement, l'évolution du volume de production de chaque série ou type et leur participation au commerce de Cadix (données complémentaires dans Sáez, 2018: 19, fig. 2). 
un intérêt prioritaire à maintenir l'ordre dans une région riche en ressources, et à garantir l'accès et/ou l'exploitation de ses nombreux gisements métalliques (argent, étain, or, etc.). De ce point de vue, le déploiement des forces militaires romaines sur terre et sur mer semble avoir été accompagné par un renforcement des relations économiques avec les principaux partisans de l'État romain dans ce secteur, en particulier la ville alliée de $G a$ dir/Gades. Par la suite, la richesse des ressources et matières premières de l'Ulterior a contribué à renforcer la présence de l'Urbs, via l'implantation d'agents destinés à développer l'exploitation de ces ressources.

\section{La première expansion du commerce gadi- tain durant l'époque républicaine (vers 150- 80 av. J.-C.)}

La deuxième moitié du deuxième siècle av. J.-C. représente un tournant dans l'histoire économique de Gadir/Gades. Cette période constitue une véritable phase d'essor économique et politique pour les villes de la province de l'Ulterior, phénomène qui semble s'accélérer surtout à partir de la fin du IIe siècle avant J.-C. (Des Boscs-Plateaux, 2014: 169-172). Bien que cette croissance économique soit bien attestée par les sources textuelles, elle est encore plus évidente dans le cas de Gadir/ Gades à la lumière de la documentation archéologique. En effet, les données matérielles de cette période témoignent d'une profonde réorganisation de l'appareil productif gaditain, en relation avec l'augmentation du nombre d'infrastructures artisanales dédiées à la fabrication et à la commercialisation des salaisons de poissons, un constat qui concerne aussi bien les fabriques que les ateliers d’amphores (García et Sáez, 2018; Sáez, 2010: 901905). Ces changements affectent non seulement le volume global de la production mais aussi, de manière significative, sa géographie ainsi que la typologie et la technologie des fours, l'organisation des zones dédiées au tournage et à la décantation de l'argile, la composition des pâtes utilisées pour les amphores, etc. Les ateliers et fabriques qui étaient actifs lors de la phase précédente ont alors été l'objet de profondes rénovations tout au long de la deuxième moitié du siècle, étant progressivement remplacées par de nouveaux contextes productifs situées à la fois dans les mêmes espaces et, surtout, dans la ceinture périurbaine de Gadir/Gades (Sáez et Lavado, 2019). Ateliers, fabriques et au- tres productions stratégiques semblent alors se concentrer en certains points de l'espace insulaire (la nécropole, dans la zone sud d'Antipolis, etc.) et dans l'embouchure du Guadalete, en prélude à un développement de l'activité industrielle qui se cristallisera et se multipliera dans la phase tardive républicaine et augustéenne.

Cette augmentation apparente du volume de production n'aurait pas dû être limitée aux fruits de mer, bien que ceux-ci aient fourni davantage de preuves matérielles. En fait, d'autres sources indiquent que la culture céréalière et la viticulture se sont également développées de manière significative dans l'Ulterior depuis le milieu du IIe siècle avant J.-C. (Martín et al., 2017: 206-218), une dynamique qui semble être principalement liée à la ville de Gadir/Gades (comme le suggère la colonisation et l'occupation du territoire insulaire et des bords continentaux de la baie, voir García, 1998). L'augmentation des niveaux de production semble s'être accompagnée d'un élargissement considérable du champ de distribution des produits de Cadix conditionnés dans des récipients en céramique. Ainsi, les amphores locales du punique tardif semblent être devenues beaucoup plus répandues sur les "marchés" traditionnels de la zone atlantique depuis environ 150/140 avant J.-C. (Arruda et al., 2013; Sousa, 2017: 197-202; Viegas, 2011: 94-98). Cette expansion du commerce de Cadix s'est également traduite par un impact plus large (en termes géographiques), puisque les amphores de Cadix sont arrivées dans des régions où elles n'étaient pas arrivées auparavant avec assiduité, comme dans le cas de la Gaule du Sud (Luaces, 2016) et de la péninsule italienne (Bernal et Cottica, 2019). De même, on peut constater que des conteneurs comme le T-9111 ont connu un grand succès dans les marchés représentés par les armées romaines en lutte et en progression vers l'ouest et le nord de l'Hispanie, comme le montre leur dispersion dans les bassins du Tage et du Guadiana, ou leur présence dans les camps romains installés lors du siège de Numance (Sanmartí, 1985: 142-150).

Les transformations urbaines liées à l'essor économique du milieu du deuxième siècle avant J.-C. sont particulièrement profondes dans le cas de Gadir/Gades, notamment en ce qui concerne l'organisation spatiale des activités de production. Il est vrai que le territoire insulaire de la ville phénicienne ne représentait pas un espace adéquat pour l'expansion de l'espace productif. Même dans le cas des activités liées à l'industrie de la pê- 
che, dont les matières premières proviennent de la mer, il était nécessaire de disposer d'un espace sur terre pour développer l'exploitation de sel, établir des usines et produire des amphores pour l'exportation. Il est significatif que certains de ces contextes de production halieutique se soient ensuite installés dans la ceinture suburbaine insulaire de la ville à partir de cette époque, comme le suggèrent les découvertes faites de part et d'autre du "canal de la baie" et en particulier le secteur de la rue Gregorio Marañón (Frutos et Muñoz, 1996: 138), un complexe de production qui a récemment été réexaminé grâce à la fouille du site voisin du bâtiment universitaire El Olivillo (Bernal et Vargas, 2019: 268-291). Ces études récentes ont mis en évidence l'existence d'une grande décharge, définie comme un éventuel "testaccio haliéutico", une zone rattachée au canal dans laquelle les structures productives environnantes déversaient les déchets de leurs activités de production et de transfert portuaire. Ce dépôt à grande échelle est donc un témoignage précieux de l'expansion économique et commerciale des activités de pêche à Gadir/Gades. De ce point de vue, il est intéressant de noter que les niveaux à la base de cette grande décharge halieutique sont datés d'environ 125-80 av. (Bernal et Vargas 2019: 256-258). Des signes de prolifération d'ateliers de poterie et de salaison, ou encore de pourpre, ont également été documentés en des points proches ou à la limite sud du pomerium de l'île (Bernal et al., 2011), en plein contact et en interaction avec la nécropole et avec des établissements ruraux dispersés. La localisation des activités productives dans les environs de la zone urbaine de la ville représente également une rupture avec le modèle de production de la zone spécialisée en vigueur à l'époque préromaine, du moins si l'on considère les preuves disponibles aujourd'hui, montrant les signes, vers 150-80 avant J.-C., d'une occupation plus articulée et intensive à la fois dans l'espace insulaire (au départ) et sur le continent.

À une époque où toute la zone côtière autour de la baie a vu l'installation de nouvelles structures de production, et où la ville de Gadir/Gades a connu une croissance économique importante, de nouveaux modèles de fours ont été introduits, inspirés des infrastructures de production de l'Italie romaine. Ce transfert de techniques romaines dans le cas des ateliers de Cadix est bien illustré par les sites de Pery Junquera (fours à griller rectangulaires ou arqués) et de l'Avenida de Portugal (grils préfabriqués), qui ont tous deux des structures en usage vers 125/100 av. (Bernal et al., 2010: 32). Cette relative "romanisation" de l'infrastructure productive s'observe plus largement au niveau de l'organisation des unités de production, marquée par l'apparition de structures comparables au modèle de la villa romaine, phénomène qui représente une autre transformation par rapport au modèle productif pré-romain (Bernal et al., 2005; Sáez, 2010: 903). Les différentes enquêtes menées dans la zone de la baie de Cadix ont permis d'identifier des dizaines de ces unités rurales (García, 1996: 55-57). L'apparition de ces structures productives conçues à la manière romaine entraîne également le développement de nouvelles formes de gestion de l'activité économique à Gadir, liées à l'utilisation d'une main-d'œuvre servile, probablement absente des ateliers de Cadix avant la période romaine (García, 2008: 92; López, 1995: 160-189; Sáez et Díaz, 2010: 286-290).

L'influence de Rome se manifeste également dans les conteneurs de transport, car le répertoire amphorique des Gadir/Gades de l'époque se caractérise d'abord par une adaptation des modèles traditionnels aux normes métriques romaines, avec une clarté particulière à partir d'environ 150/125 avant J.-C., adaptant la forme des conteneurs pour obtenir un volume proche du modus romain (environ 8,73 litres) ou de ses diviseurs/multiplications. Cette transformation du répertoire des amphores semble s'accélérer dans la seconde moitié du IIe siècle avant J.-C., avec la disparition des formes de la tradition punique (T-12112 et T-8211, et plus progressivement celles du type T-9111, lequel avait encore avec un certain poids au début du Ier siècle avant J.-C.), au profit de modèles plus conformes aux normes romaines de forme et de capacité (T-7430 et Dressel 1) (Ramon, 1995: 210-213; Sáez et Luaces, 2019). Le développement local du type Dressel 1, emballage fondamental de la production de vin dans l'Italie républicaine, témoigne clairement de cette "romanisation" du matériel et des stratégies associées aux activités économiques dans la production alimentaire (ce que laissait déjà entrevoir l'essor précédent de la fabrication de versions "gréco-italiennes"). La disparition des sceaux liés aux gemmes ou bagues signataires (ou aux matrices basées sur celles-ci) et l'utilisation des premiers sceaux épigraphiques (en punique, mais surtout en latin, comme tria nomina), autre pratique absente dans les ateliers de Gadir avant $150 / 125$ environ avant J.-C., est un autre exemple 
de cette influence des activités économiques romaines. Ce même modèle d'estampillage témoigne, en effet, d'un renforcement de la volonté des élites locales liées à ces entreprises de se vêtir de formules romanisées de propagande et de gestion, dans un cadre général qui semble être défini par une adaptation de toute la structure économique de la ville aux normes romaines (García, 2008: 98100). Les timbres épigraphiques de cette phase, qui semblent avoir été particulièrement populaires dès la fin du IIe siècle et les premières décennies du Ier siècle avant J.-C., s'inspirent clairement des cartouches rectangulaires des timbres tunisiens de "l'Afrique ancienne" (Magon) ainsi que des timbres présents sur les conteneurs ovoïdes, lesquels reflètent conjointement le caractère plus internationale et méditerranéenne du répertoire amphorique local à partir de ces décennies face à une tradition punique locale en voie de disparition.

Indépendamment des transformations subies par les techniques de production et les institutions économiques, c'est surtout du point de vue de l'extension des réseaux commerciaux que l'immersion dans le monde romain se fait le plus sentir pour cette seconde phase des années 150-80 avant J.-C. Dans ce point de vue, il semble que les nouveaux marchés atteints durant cette période étaient plus ou moins directement liés à l'expansion romaine en Méditerranée occidentale (Figura 5). Si les fameuses salaisons de poisson et sauces de Gadir/Gades semblent avoir représenté l'essentiel des produits en circulation, le vin produits dans les campagnes de Gadir, et même l'huile, ont dû également être des marchandises exportées à grande échelle durant la seconde moitié du IIe siècle avant J.-C. (Bernal et Vargas, 2019: 268-291). Quant aux contextes de consommation dans la péninsule, les produits de Cadix ont participé en premier lieu à l'approvisionnement des troupes romaines. Ceci est démontré par la représentation quantitative significative des conteneurs de Cadix parmi les différentes zones associées aux activités militaires de Rome, qu'il s'agisse de tours/forteresses dédiées à la sécurisation du territoire, comme c'est le cas des sites de El Santo de Valdetorres et El Castillejo (Heras et Bustamante, 2007: 320; Pérez et Delgado, 2011: 66-68), ou pour l'approvisionnement de camps militaires liés à certaines des grandes opérations militaires de Rome, comme dans le cas des camps construits pendant le siège de Numance (Sanmartí, 1985: 142-150). Les résultats obtenus dans le Guadiana, dans différen- tes parties de l'Algarve (Viegas, 2011: 92-98), à Olisipo (Sousa et al., 2016: 466-468), dans les Rias galiciennes (Ferrer et al., 2019: 91-95), mais aussi dans le réseau d'établissements de la côte atlantique de la Maurétanie (de Lixus à Mogador), illustrent un commerce actif dont l'épicentre se situe dans le port de Gadir/Gades qui apportait à la ville des matières premières, des esclaves, des animaux exotiques et diverses manufactures, qui étaient à leur tour redirigés vers les principaux réseaux méditerranéens en compagnie de poissons salés et de vins locaux.

Du côté méditerranéen, les perspectives sont similaires. Les produits et les conteneurs de $\mathrm{Ga}$ dir peuvent également être trouvés dans plusieurs centres urbains directement liés au renforcement du réseau urbain et administratif romain, comme le suggèrent les résultats enregistrés dans deux points portuaires clés de la province de Citerior: Carthago Nova et Tarraco. Dans ces deux cas, les contextes de consommation datant d'environ 200150 avant J.-C. montrent une représentation assez faible des conteneurs dans la région du détroit de Gibraltar (entre 2 et $5 \%$ ), largement illustrée par les amphores de Gadir. Cependant, la proportion de produits provenant de cette source dans les deux points de consommation augmente considérablement à partir d'environ 150 avant J.-C., atteignant près de $40 \%$ des importations dans le cas de Carthago Nova (Murcia et al., 2013: 125126), et près de $10 \%$ des amphores de la région du détroit dans le répertoire d'amphores de Tarraco (Díaz, 2016: 170-173). Il est intéressant de noter que cette croissance des importations de Cadix semble s'être faite au détriment des produits et des conteneurs italiens (Díaz, 2016: 170). En effet, les données amphoriques nous permettent de dessiner un scénario dans lequel Gadir/Gades, une ville alliée, a réussi à gagner des parts de marché en approvisionnant deux des principales villes de l'administration romanisée de Citerior, au détriment des principaux centres de production de l'Italie romaine (bien que la consommation de vaisselle, de vin et d'huile italienne serait très importante dans toute la région, comme le suggèrent les données des contextes républicains de Valence et d'autres cas largement étudiés, voir Carreras et al., 2017; Molina, 1997; Ribera, 1998).

L'augmentation des exportations de Cadix est encore plus évidente si l'on examine le contexte de la Gaule du Sud, un secteur dans lequel ses exportations ont eu peu d'impact au cours des premières 
décennies de la phase républicaine romaine. En particulier, on observe une nette augmentation de la proportion d'amphores de Cadix dans plusieurs villes romaines de la région, notamment Narbo Martius et Toulouse (Loughton, 2016: 119; Sanchez, 2009: 119-162), mais aussi dans des sites encore sous l'influence de Massalia, comme Olbia de Provence (Luaces, 2019: 771). Les données quantitatives dans la plupart des contextes républicains étudiés offrent une proportion d'amphores estimée entre 10 et $15 \%$ pour la période d'environ 125-80 avant J.-C., alors que cette proportion était presque nulle auparavant (Díaz, 2016: 170173; Luaces, 2019: 770-771). Divers contextes du sud de la Gaule associés à l'exploitation minière montrent également une offre importante de produits de Cadix, comme dans le cas des gisements de Lascours et Les Martys (Benquet, 2016: 225226; Luaces, 2016: 706-709). Il faut également noter que plusieurs découvertes le long des côtes de la Gaule du Sud témoignent de l'intérêt du marché français pour les produits gaditains, comme le montre le cas de l'épave du Chrétienne M2 (Luaces et Sáez, 2019). Enfin, on note que les produits de Cadix ont également atteint le sud et le centre de l'Italie durant les années 150/80 avant J.-C., comme le montrent les données archéologiques des villes de Pompéi et Albintimilium (Bernal et Sáez, 2019; Lamboglia 1955; Maria et Dominicis, 2020), un changement de tendance remarquable étant donné que les produits de Cadix n'étaient pas largement distribués dans cette région avant cette période.

L'essor économique considérable que la ville de Gadir a connu à partir des années 150 avant J.-C. s'observe également dans d'autres registres matériels. La documentation archéologique témoigne en effet d'une expansion considérable des réseaux commerciaux de Cadix durant cette période, et les produits de la ville ont atteint de nouveaux centres de consommation et de nouveaux marchés durant cette période. Cette expansion commerciale a fait de Gadir l'un des principaux centres économiques de la Méditerranée occidentale. Les effets de cette projection commerciale sans précédent (phénomène peut-être même plus im-

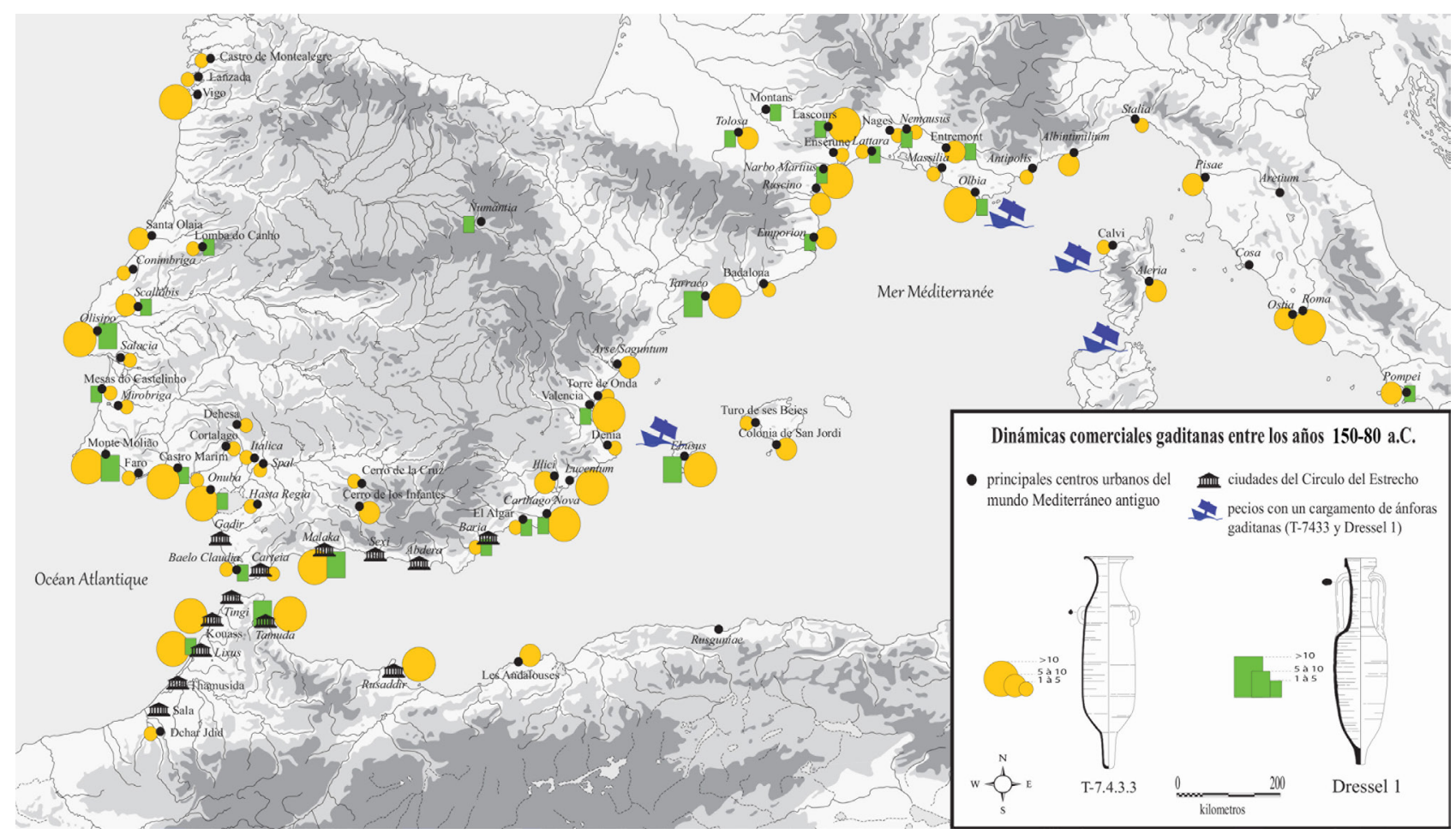

Figura 5. Carte de dispersion actualisée affichant la diffusion des conteneurs gaditains de la période républicaine, centrée dans ce cas sur les types T-7433 et Dressel 1. L'influence socioculturelle de l'Urbs s'avère ici évidente, le type Dressel 1 - le principal support du commerce vinaire de l'Italie romaine - étant incorporé dans les registres de production de la ville fédérée de Gadir durant cette période. Si l'on compare ces données de diffusion avec celles de l'étape précédente (Figura 4), on peut constater que les amphores des années 150-80 avant J.-C. ont eu une diffusion beaucoup plus large, tant en termes d'extension géographique des réseaux d'échange qu'au niveau des volumes exportés. 
portant que celui observé pour le Ve siècle avant J.-C.) sont visibles tant au niveau de l'urbanisme, avec la mise en place de nouvelles structures productives, que dans l'organisation des activités économiques, qui se caractérise par une rupture visible avec le modèle productif préromain de la ville. La commercialisation des produits de la pêche était l'une des principales activités de la ville (García, 2008), mais cet essor économique s'est également traduit par l'installation de nouvelles structures agricoles (Bernal et Vargas, 2019: 220222), probablement liées à la viticulture, à la culture céréalière et à l'élevage lié au textile, ainsi que par le développement de la production de substances parfumées (Sáez et López, en prensa) et de teintures pourpres (Bernal et al., 2011; Bernal et García, 2014). Ce développement des activités de production s'est naturellement accompagné d'une augmentation des excédents destinés à l'exportation, même s'il ne faut pas sous-estimer le rôle de Gadir/Gades comme port de redistribution vers/ depuis l'espace atlantique, rôle charnière que la ville jouait déjà depuis au moins le Ve siècle avant J.-C. comme principal interlocuteur des réseaux maritimes méditerranéens (Fantuzzi et al., 2020; Sáez, 2018). En fait, l'augmentation du volume des produits italiens dans de nombreux endroits de l'espace atlantique semble avoir été liée à cette expansion commerciale de Cadix: alors que la ville drainait les ressources de l'Atlantique et de l'intérieur péninsulaire (avec sa connexion au Guadiana et à Hispalis-Guadalquivir), et même au-delà, elle recevait des produits manufacturés et alimentaires d'Italie, de Gaule et d'Afrique du Nord, les redistribuant dans les deux sens et introduisant ses propres produits dans les cargaisons. Malacca et Carteia ont dû être deux concurrents importants à ce stade, surtout en raison de la plus grande composante de la population italienne qu'elles abritaient et du fait qu'à travers le corridor d'Antequera un accès alternatif aux ressources métallifères de la Sierra Morena a été ouvert (Mateo, 2016). On notera cependant que les géographes grecs et latins ont présenté la ville de Gadir non pas comme un port maritime extérieur, mais comme la fin des routes maritimes de la Méditerranée (Moret, 2012: 442-443), une description qui témoigne une fois de plus du rôle central joué par la ville dans les échanges entre ces deux domaines maritimes.

On peut chercher diverses explications à cet essor économique. Une fois de plus, les premières raisons se trouvent dans la situation géostratégi- que de la cité, au carrefour de différents axes maritimes et terrestres. L'expansion militaire des Romains vers la frange atlantique, qui s'est accélérée dans les décennies qui ont suivi les conflits avec les Lusitaniens (comme l'illustre l'expédition de Decimus Junius Brutus en Galice en 138/137 av. J.-C.), semble avoir naturellement profité à ce fidèle allié de Rome (Morais, 2007: 101-104). De ce point de vue, Gadir/Gades a pu profiter de sa position centrale sur les routes maritimes de l'Atlantique, puisque ses flottes et ses marins étaient des experts de la navigation dans la Mer Extérieure. Les besoins des forces militaires romaines en campagne induisaient un approvisionnement constant et la cité de Gadir était dans une excellente position pour fournir le ravitaillement nécessaire aux légions engagées dans les théâtres d'opérations ibériques. De fait, les commerçants de la ville pouvaient compter sur le contrôle des principales voies de communication, notamment celles liées aux axes fluvio-maritimes (Arnaud, 2016; 2019: 210-212). Le développement de l'activité minière en Ibérie nécessitait également un approvisionnement important, tant pour les agents de l'Urbs que pour la masse des travailleurs, essentiellement d'extraction servile mais qu'il fallait pouvoir nourrir afin qu'ils accomplissent leur dur labeur. L'expansion militaire et économique entreprise par les Romains dans le centre et le nord de la péninsule ibérique représentait donc une grande opportunité pour les marchands et les artisans de Gadir. Cette situation pourrait expliquer la première impulsion donnée aux activités de production et à la diffusion des produits de Cadix entre 150 et 125 avant J.-C. environ. L'enrichissement de ses élites et le renforcement des relations avec celles de Rome semblent avoir contribué, dans un deuxième temps, à maintenir le dynamisme économique de Gadir. L'installation de nouveaux agents italiens dans la région, à partir de la fin du IIe siècle avant J.-C., allait alors ouvrir un nouveau marché pour les produits halieutiques et autres marchandises en provenance de Cadix ou redistribuées par cette cité. De fait, le renforcement de la demande en Hispanie, puis dans les nouveaux axes de l'expansion romaine en Méditerranée occidentale, notamment le sud de la Gaule, a ouvert de nouveaux marchés pour les produits gaditains. Finalement, bien que les élites phéniciennes de la ville aient disposé d'une relative autonomie politique par rapport à Rome, elles ont été les premières bénéficiaires de ce rapprochement avec les intérêts romains. L'ono- 
mastique des marques épigraphiques sur les amphores T-7433 datées de la période 125-80 avant J.-C. sont un exemple éloquent des changements de mentalité ayant touchés les oligarchies de Cadix de l'époque, et de leur intérêt à s'adapter rapidement à un nouveau panorama alors dirigé par Rome. Il semble donc que l'ancienne aristocratie de Gadir ait été l'un des moteurs des changements économiques, techniques et culturels que la ville a connus, phénomène qui a été une conséquence naturelle du rapprochement avec Rome (et avec certaines des familles proches du pouvoir en particulier) et de l'intégration et du succès des marchandises de Cadix dans les réseaux commerciaux romains, ces derniers leur ayant ouvert l'accès à des marchés auparavant fermés ou difficile d'accès pour les Gaditains.

\section{L'apogée du commerce républicain de Gadir (vers. 80-40 av. J.-C.)}

Après une première période de croissance économique remarquable entre 150 et 80 avant J.-C., Gades a connu une deuxième phase de croissance qui a conduit à son apogée en tant que centre commercial majeur dans la région du détroit à partir d'environ 80 avant J.-C. (probablement après le conflit sertorien et ses bouleversements, profitant d'une autre situation délicate pour se positionner du bon côté et fournir des troupes, voir Des Boscs-Plateaux, 2014). Cet essor est essentiellement le résultat de la poursuite de la dynamique économique précédente, notamment le soutien continu des élites de Cadix pour l'approvisionnement des contingents romains dans la péninsule. Cependant, le développement économique généralisé du monde méditerranéen de la fin de la République (Hollander, 2007: 153-155; Bowman y Wilson, 2009: 28-35), désormais entièrement sous le contrôle de Rome, a également contribué à amplifier le dynamisme commercial propre au cas de Cadix. En fait, la ville a connu à ce stade une nouvelle expansion de ses infrastructures de production, ainsi qu'une nouvelle expansion de ses réseaux et de ses routes commerciales, toujours étroitement liés à l'expansion romaine. À partir de cette époque, et surtout de la fin du 1er siècle avant J.-C., les produits agricoles de la ville ont commencé à être exportés d'un bout à l'autre du monde méditerranéen, et même au-delà (à l'est et dans l'Atlantique Sud et encore plus au Nord).

Pour caractériser cette phase d'apogée au mi- lieu du premier siècle avant J.-C., il est nécessaire de commencer par examiner les changements d'urbanisme et d'organisation spatiale qui ont marqué la ville de cette époque. Ces années centrales du premier siècle avant J.-C. se caractérisent tout d'abord par un large développement des activités de production, avec une exploitation plus dense de nouvelles parties du territoire de la Baie, tant sur sa rive continentale que sur la zone insulaire. C'est le cas de l'ancienne île d'Erytheia, à l'extrême nord de l'archipel où était située la ville de Gades (Bernal et Vargas, 2019: 220-222), et en général de toute la ceinture d'îles périurbaines. Dans ce dernier cas, il semble que l'objectif d'accroître la productivité et l'exploitation de ces zones concernait à la fois le transfert portuaire et la production de produits dérivés de la mer (salaisons, teintures, etc.) et l'extension des activités agricoles. En outre, à ce stade, l'établissement de nouvelles structures de production similaires au modèle de la villa romaine a également été détecté (Bernal et al., 2005; Sáez, 2010: 903-905). Ces nouvelles "villae" ont été installées dans toute la ville, poursuivant la dynamique de la phase précédente. Ainsi, contrairement à la période précédente, l'installation de ces nouvelles structures productives ne se limitait plus à la zone insulaire de la baie ou à l'embouchure du Guadalete et de l'Iro (deux enclaves portuaires essentielles); de nouvelles zones du continent commencent à être exploitées durant la phase 80-40 avant J.-C., avec la construction de "villae" le long des rivières liées à la baie (Díaz et Sáez, 2016; Sáez et Carrero, 2018: 192-195). Il convient de noter que cette deuxième expansion des activités de production représente une nouvelle rupture avec le modèle préromain de peuplement de Cadix et se rapproche du modèle romain d'utilisation des terres, avec l'apparition de zones consacrées à l'agriculture intensive (ce qui laisse supposer qu'il y a probablement eu d'autres siècles à ce stade). D'autres pratiques en vogue dans l'Italie romaine de la fin de la République se sont également répandues dans la ville, avec l'utilisation de plus en plus répandue de divers éléments architecturaux romains, tels que les tégulas et les briques cuites de différents types (Sáez et Carrero, 2018: 189-191). La construction de bâtiments et d'infrastructures publiques inspirés de l'Italie romaine, tels que les citernes, les bains, les fontaines, les aqueducs et le théâtre (Dios, 2011; Lara, 2018: 142-145), témoigne également de la mise en œuvre à Gades du modèle d'urbanisme romain 
au milieu du Ier siècle avant J.-C., à une époque où ses citoyens avaient reçu la pleine citoyenneté romaine, attribuée par César en 49 avant J.-C. (Dion Cassius, 41, 24, 1). En effet, plusieurs répertoires matériels témoignent de cette "romanisation" du mode de vie des habitants de Cadix entre 80 et 40 avant J.-C., que ce soit en statuaire, en céramique de cuisine ou en épigraphie (Ferreiro, 2008; García et García, 2010; Ventura et Dios, 2011). Ce phénomène s'est produit à une époque où la ville connaissait une prospérité sans précédent, comme l'illustrent les 14 rangées de sièges occupées par des individus de rang équestre lors des jeux organisés par Cornelius Balbus en 43 av. (Cic. Epistolae ad familiares, XII, 32). Au vu des données fournies par les recherches archéologiques récentes et par l'examen des sources écrites ou épigraphiques, il est clair que cette riche aristocratie de Cadix a pu prospérer grâce à ses liens sociaux, à sa stratégie appropriée de soutien inconditionnel aux factions gagnantes, et au développement parallèle des activités économiques et de l'expansion du commerce maritime, bénéficiant toujours du soutien obtenu grâce à l'influence de familles comme les Balbo à l'apogée du pouvoir romain.

Du point de vue du commerce, il existe d'autres signes qui montrent la profonde adaptation de l'économie de Cadix aux pratiques romaines. Les amphores tardo-puniques disparaissent en effet des répertoires locaux, entre 80 et 60 avant J.-C. environ (sauf T-7433, qui a duré jusqu'au début de la phase augustéenne dans certains ateliers ou secteurs de production). La romanisation formelle et métrique du répertoire est un fait à partir de cette phase, avec un poids plus important de formes ovoïdes (les "Ovoïdes gaditanes" et peut-être le type Ovoïde 1), peut-être inspirées par des prototypes du sud de l'Italie, et des versions locales du Dressel 1C (García et al., 2011: 257-259; Quillon 2016: vol. 1, 144-149). Ces ovoïdes de Cadix ont été fréquemment confondus avec les types de robes 7 et 9/10, et bien qu'ils semblent avoir un lien familier, il s'agit néanmoins de séries différentes, les premiers apparaissant vers 80/70 avant J.-C., tandis que les seconds apparaissent plutôt à partir de 40/30 avant J.-C. (García, 1998; Lagóstena et Bernal, 2004). Les amphores Dressel 1C et les amphores ovoïdes de Cadix, deux modèles de conteneurs principalement destinés au transport de dérivés du poisson, ont été initialement fabriquées en même temps que les amphores T-7433, comme l'illustrent les données des con- textes de production dans toute la baie de Cadix, avec des cas paradigmatiques comme celui de l'atelier Jardín de Cano (López, 2008: 35-36) ou la plupart des ateliers de l'Antipolis de l'époque, comme le Cerro de la Batería, les Gallineras ou la Calle Asteroides (García et Sáez, 2018). Moins de trois décennies plus tard (une génération), les ateliers de Cadix ont produit principalement des conteneurs Dressel 7/11 et peut-être Dressel 12. La documentation amphorique témoigne surtout d'une augmentation considérable des niveaux de production parallèlement à ce remplacement des conteneurs puniques tardifs par des conteneurs entièrement romanisés ("provinciaux", selon García et al., 2011). Ainsi, les données matérielles semblent indiquer que la commercialisation des produits halieutiques et agricoles a connu un essor important au milieu du premier siècle avant J.C. (pas seulement celles conditionnées en amphores), en fonction de l'augmentation du nombre de zones de production. Les découvertes d'El Olivillo caractérisent ce double phénomène dans la ceinture périurbaine autour du canal, car les niveaux des années 80-40 avant J.-C. sont caractérisés par une augmentation du nombre de conteneurs associés de ces types romanisés, liée à la disparition progressive des conteneurs puniques tardifs de la phase précédente (Bernal et Vargas, 2019: 257 262).

L'augmentation du volume des amphores en circulation, en accord avec le développement de modèles de conteneurs d'inspiration romaine, s'est également accompagnée par une nouvelle expansion des réseaux commerciaux fluvio-maritimes et d'une augmentation des volumes exportés. Il convient de noter que cette augmentation des exportations de Cadix, datant d'environ 80 à 40 avant J.-C., s'est produite dans le contexte d'une croissance généralisée du commerce à l'échelle de la Méditerranée occidentale (Quillon et Luaces, 2019: 299-301). Certains indicateurs indiquent une forte augmentation des exportations de l'Ulterior en général, comme le montre l'épave du "Titan" et sa cargaison de milliers d'amphores de poisson salé en provenance de Malaga (Quillon et Capelli, 2016) pour le cas de la Gaule du Sud.

Ces données mettent en perspective l'augmentation des exportations du Gades durant cette phase. Cependant, la croissance observée dans le cas du Gades s'avère particulièrement significative, surtout si l'on compare la répartition des amphores puniques tardives de type T-7433 avec celle des 


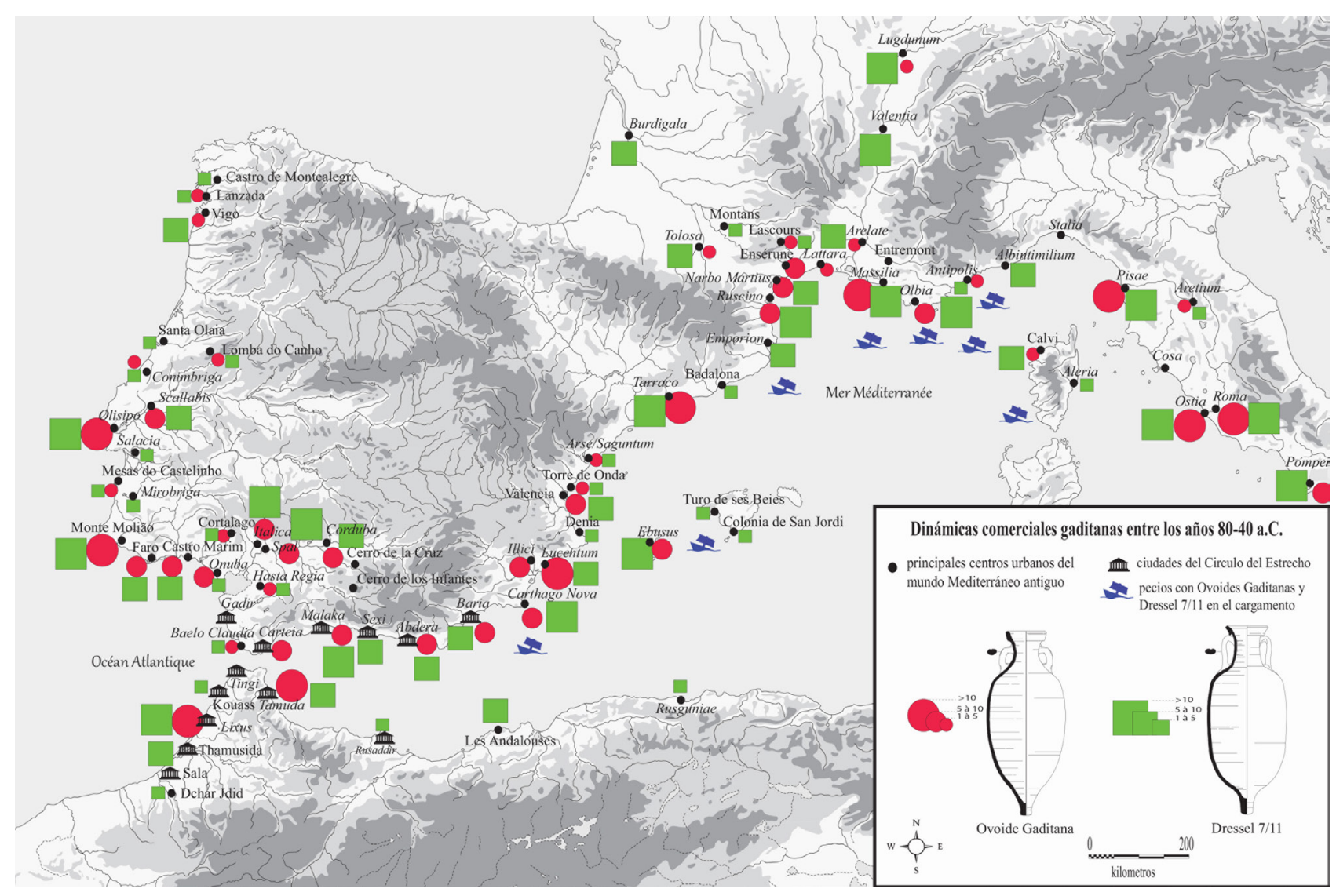

Figura 6. La phase d'essor économique et commercial de la Gadir romaine, illustrée par la très large diffusion des amphores à salaisons, est représentée sur cette carte par la grande dispersion des principaux conteneurs des années 80-40 avant J.-C., à savoir les types ovoïdes gaditanes et Dressel 7/11. À partir de cette époque, la nouvelle ville de Gades, qui avait obtenu le statut de municipe de droit romain, était devenue l'un des centres économiques les plus dynamiques du monde romain, en exportant ses amphores du littoral atlantique au Levant, de la Bretagne à la frontière méridionale des provinces d’Afrique du Nord.

conteneurs Dressel 1C, Ovoide Gaditana et Dressel 9/10 (Figura 6). Une commercialisation nettement plus importante de ces trois dernières séries d'amphores est observée dans des sites tels que Tarraco, Ampurias, Scallabis et le site de Castro Marim (Díaz, 2016: 179-180; González et al., 2018; Viegas, 2011: 99-104). En outre, plusieurs sites ont proposé des ensembles d'amphores datant du milieu du Ier siècle avant J.-C., dans lesquels on trouve des quantités remarquables d'ovoïdes de Cadix et de Dressel 9/10, alors qu'à ces mêmes endroits, peu (ou pas) d'amphores de Cadix avaient été détectées dans les ensembles de matériel datant des années 150-80 avant J.-C. Dans le cas du sud de la Gaule, les contextes tardo-républicains de Narbo Martius et du site minier de Monrouch (Montagne noire) illustrent la forte croissance des importations de Gades entre 120-80 avant JC et 80-40 avant JC. (Benquet, 2016: 216 et 225; Sanchez, 2009: 139153): A Monrouch, le nombre d'amphores identi- fiées est passé de 4 à 14, tandis qu'à Narbonne, le nombre d'amphores salées d'Ulterior, et en particulier de Gades, a augmenté de près de $200 \%$. D'autres villes du sud de la Gaule enregistrent les premières preuves de la consommation d'amphores de Cadix vers 80-40 avant J.-C. C'est le cas des cités de Burdigala, Massilia et Lugdunum, trois agglomérations dans lesquelles aucune amphore T-7433 n'a été identifiée, alors que les types Dressel 12 et Dressel 7/11 sont relativement bien représentés (Quillon et Luaces, 2019). Plusieurs sites en Italie présentent également un schéma similaire, comme l'illustrent les contextes républicains tardifs des villes de Rome et d'Ostie (Rizzo et Moreno, 2019). En fait, la distribution des amphores de Cadix à partir de cette phase, surtout dans sa dernière partie, remonte à l'Angleterre, à la Germanie (Carreras et Morais, 2012: 430-433), au sud de l'actuelle Tunisie, et d'Olisipo sur la côte atlantique portugaise à Délos et Athènes en Méditerranée orientale (Liou, 
2000). Jamais auparavant les marchandises de $\mathrm{Ga}$ des n'ont été aussi largement distribuées, tant en termes de volume exporté - surtout dans le cas des amphores - que d'étendue géographique de leur circulation. Pour cette période (env. 80-40 av. J.-C.), les données des contextes et épaves sous-marins attestent également de ce pic du commerce maritime opéré à partir de la baie de Cadix, comme l'illustrent les cas des épaves du Grand-Congloué 3 (Sáez et Luaces, 2014), ainsi que l'épave du Planier 5, deux navires découverts au large des côtes de la Gaule du Sud avec une cargaison constituée principalement d'ovoïdes de Cadix (Quillon, 2016: vol. 2, 36-38).

À partir des années 40/30 avant J.-C., Gades, dont l'élite avait déjà la citoyenneté romaine et occupait une position stratégique dans les cercles de pouvoir de la ville, a poursuivi le processus de croissance économique qui l'avait transformé en l'une des communautés les plus riches et les plus peuplées du monde républicain tardif. Le rapprochement avec la cause de César, puis avec celle d'Octavien (Des Boscs-Plateaux, 2005: 39-52; Ferreiro, 2008: 319-322), lui a permis de bénéficier de nouveaux privilèges et d'un soutien politique au sein du pouvoir romain, ce qui a sans doute contribué à générer de nouvelles opportunités commerciales (au moins pour certaines familles) dans des secteurs liés à l'approvisionnement de l'État et de l'armée. Par conséquent, cet ancien établissement phénicien a mis fin à la période républicaine tardive en devenant une véritable "ville nouvelle" (la Neapolis attribuée aux Balbo), devenant une ville romaine à part entière vers 19 avant J.-C. (Pline, N.H. 4, 36, 11) mais aussi en remodelant ses mentalités, sa sociologie et ses stratégies économiques (comme le suggèrent les nouvelles émissions monétaires, en plus des autres aspects déjà mentionnés). Cette nouvelle Gades romain continue de marquer l'histoire économique et politique du sud de la péninsule ibérique et de la région du détroit, même s'il va progressivement s'orienter vers une période de déclin en raison de multiples facteurs, dont l'influence croissante des colonies de la vallée du Guadalquivir dirigées par Hispalis et surtout Corduba (Des Boscs-Plateaux, 2005).

\section{Conclusions}

Tout au long de cette contribution, nous avons tenté de mettre en lumière comment la ville de Gadir/Gades avait connu un essor économique croissant à partir du IIIe siècle avant J.-C., et en particulier entre la deuxième guerre punique et la période césarienne-augustéenne. Les évènements politiques et économiques qui avaient pu conduire à l'ascension sociale des élites de Cadix dans le monde romain avaient jusqu'à présent été une source de discussion. La documentation archéologique abordée dans ces pages nous permet de clarifier certains des phénomènes qui ont conduit à cette ascension et à un enrichissement croissant de l'aristocratie de cette cité de la région de Gibraltar. Paradoxalement, le principal fondement de ce processus se trouve dans le passage de la ville à l'orbite de Rome. Loin d'être la cause d'un éventuel déclin, la conquête romaine du sud de l'Ibérie a, au contraire, offert de nouvelles opportunités aux élites d'une ville déjà puissante, grâce à sa position de charnière de deux importants domaines maritimes. En fait, cette aristocratie avait rapidement rejoint le camp romain lorsque le conflit contre les Carthaginois semblait devenir un désavantage. Bien que la ville ne semble pas avoir subi de contrôle direct de Rome au cours du IIe siècle avant J.-C., elle a été rapidement marquée par l'influence des nouveaux maîtres de la Méditerranée. Cette influence était d'autant plus importante que l'appareil économique local était nécessaire pour soutenir l'expansion de la péninsule romaine et de l'Atlantique. Les trois phases d'expansion économique et commerciale identifiées pour la période républicaine tardive témoignent de ce lien étroit entre le développement des activités de production, l'extension des réseaux commerciaux de Cadix et l'expansion de l'influence romaine en Méditerranée occidentale. La circulation de plus en plus répandue des amphores à salaisons de Cadix, l'un des produits pour lesquels la ville était réputée, témoigne de cette expansion commerciale: les produits de Cadix étaient principalement distribués au niveau régional au cours du IIIe et du début du IIe siècle avant J.-C, En relation avec les circuits commerciaux traditionnels de la ville le long de la côte atlantique, entre 150 et 80 avant J.-C. environ, on peut identifier une période cruciale pour le développement de l'économie de la cité, caractérisée par une circulation beaucoup plus importante des marchandises de Cadix, plus particulièrement vers le nord de la péninsule ibérique et le sud de la Gaule. L'économie de la ville a connu une nouvelle phase de croissance entre les années 80 et 40 avant J.-C., parallèlement au renforcement de l'influence romaine dans les réseaux commer- 
ciaux de la Méditerranée occidentale.

Malgré l'intérêt de cette synthèse historique et archéologique sur l'évolution des bases du commerce à la fin de la période punique et au debut de la Gades romain, la discussion sur le rôle économique et politique que cette ville a joué dans la sphère régionale atlantique et méditerranéenne peut être incluse dans un débat conceptuel plus large. Ce débat dure depuis plusieurs décennies maintenant, alors que les informations archéologiques disponibles dans toutes les sous-zones citées dans ce texte se sont multipliées en qualité et en quantité. Nous nous référons au réexamen auquel est soumis depuis plus de vingt ans le concept de "cercle du détroit", défini initialement par Miquel Tarradell $(1957,1960)$ pour la phase punique et appliqué ensuite par d'autres auteurs à la phase républicaine et impériale romaine (Ponsich, 1975) et à la phase phénicienne archaïque (J.M. Gran Aymerich, M.E. Aubet, etc.). Il s'agit d'une conceptualisation de Tarradell qui a donc été brouillée et, dans de nombreux cas, défigurée et insérée dans des débats très éloignés de ses présupposés initiaux. C'est pourquoi, au cours des deux dernières décennies, les approches réalisées par des auteurs aux positions très différentes n'ont pas manqué (Álvarez et al., 2019; Bernard, 2018; Callegarin, 2000; Coltelloni-Trannoy et al., 2016; Domínguez, 2011; Gozalbes, 2016; Hassini, 2006; Kbiri, 2006; Niveau de Villedary, 2001; Pons, 2015; Sáez et al., 2005, parmi beaucoup d'autres). En ce qui concerne l'étape historique abordée dans ces pages, les différents points de vue vont du déni absolu au soutien inconditionnel, en axant la discussion sur la possibilité réelle d'appliquer le concept à un scénario dans lequel Carthage aurait dominé l'ensemble du secteur à la fin du IIIe siècle avant J.-C. et Rome exercerait un rôle politique et prépondérant, au moins depuis l'annexion directe de la rive nord de la région.

De notre point de vue, le problème ne réside pas dans le concept ni dans son prétendu "caractère colonialiste", mais plutôt dans le traitement biaisé et inadéquat qu'en ont fait de nombreux auteurs, et le manque de rigueur avec lequel les sources écrites et archéologiques ont été analysées, amenant dans bien des cas chacun à sa sardine sans base documentaire solide. Les parallèles et les comparaisons est-ouest et nord-sud n'ont pas été suffisamment établis à l'échelle régionale et, contrairement à Tarradell, peu d'auteurs impliqués ont eu une expérience et une connaissance directes des archéologies des sous-régions clés de la zone traditionnellement incluse dans le "cercle". Le rôle de Gadir/Gades a été une pièce fondamentale dans le débat académique autour de ce concept, puisque pour Tarradell la Gadir punique devait être le centre économique et religieux du "cercle", qui comprendrait à la fois le côté ibérique et le côté maurétanien de la région géohistorique (Vanney et Ménanteau, 2004), l'interlocuteur principal du réseau urbain de la zone du détroit face à Carthage et à la Méditerranée. Le concept, cependant, est resté dans une formulation initiale et statique, manquant de profondeur suffisante dans des aspects tels que l'évolution de la situation et le rôle de Gadir et du reste des principaux centres depuis l'arrivée de Rome dans la région, ce qui a donné lieu à nombre des controverses actuelles. En outre, dans certains cas, on a voulu voir une traduction de la situation politique existante au moment où Tarradell a écrit ses œuvres (le "Protectorat" espagnol et français en lien avec le Maroc actuel) dans l'attribution que cet auteur a faite à Gadir d'un rôle hégémonique dans certaines facettes comme celle de l'économie.

En dehors de ces polémiques, souvent vides de contenu réel, les données fournies et discutées dans ces pages et dans les travaux précédents (Luaces et Sáez, 2019; Sáez, 2018) suggèrent que les approches de Tarradell étaient réellement conformes à ce que les sources archéologiques ont révélé au cours des dernières décennies. Cela ne contredit pas le fait que le "cercle du détroit" doit être ajusté et reformulé précisément en fonction de ces nouvelles données, tant en ce qui concerne la participation de chaque sous-zone au "cercle" que l'évolution diachronique du rôle de Gadir/ Gades. D'un point de vue actuel, il ne fait guère de doute que Gadir a eu, avant l'arrivée des armées romaines dans la région, un rôle majeur dans l'activité maritime et portuaire et en général dans le commerce atlantique et méditerranéen, étant la référence pour toutes les autres villes et le nœud qui reliait de multiples systèmes locaux et régionaux aux routes méditerranéennes et au réseau de "marchés" qui les interconnectait. Ce rôle a probablement été moins prononcé au début du IVe siècle, et il s'est surtout développé à partir du milieu du siècle et au cours du IIIe siècle avant J.-C. De même, et bien que formellement au cours des deuxième et premier siècles avant J.-C. La Mauritanie occidentale avait une indépendance politique par rapport à Rome et à l'Hispanie et pouvait théori- 
quement agir comme un concurrent, la vérité est que les archives de Melilla, Tamuda, Lixus, Zililil, Kuass, Thamusida, Banasa et d'autres endroits décrivent un scénario différent, dans laquelle l'impact du commerce maritime de Cadix était important, alors qu'au même moment, les flottes de Cadix parvenaient à relier leur "cercle" atlantique avec les principales routes menant à la péninsule italienne (via la Gaule du Sud ou la côte de la Sicile via le Maghreb). Le rôle de principale référence économique régional tenu par Gadir/Gades n'a pas beaucoup varié entre 206 av. J.-C. et Auguste, bien que dans cette phase, ce rôle ait été possible en tant qu'allié et base stratégique pour Rome, profitant de sa position de tremplin essentiel pour l'expansion atlantique.

\section{Bibliographie}

ALFARO ASINS, Carmen. 1988: Las monedas de Gadir/Gades. Fundación para el Fomento de los Estudios Numismáticos. Madrid.

ALVAREZ MELERO, Anthony; ALVAREZ-OSSORIO, Alfonso; BERNARD, Gwladys; TORRES-GONZALEZ, Víctor Andrés (eds.). 2019: Fretum Hispanicum. Nuevas perspectivas sobre el Estrecho de Gibraltar durante la Antigüedad. Editorial Universidad de Sevilla. Sevilla.

ARANEGUI GASCÓ, Carmen. 2001: “La campaña de excavación de 1999”. SAGVNTVM, Extra-4, pp. 109-112.

ARANEGUI GASCÓ, Carmen. 2004: "Lixus (Larache, Marruecos)". Bienes culturales: revista del Instituto del Patrimonio Histórico Español, 3, pp. 171-182.

ARHARBI, Rachid; LENOIR, Eliane. 2016: "Banasa et les circuits commerciaux du Détroit aux IIIe et IIe siècles avant J.-C." Karthago, 29, pp. 8390. Doi: 10.2143/KAR.29.0.3170072.

ARNAUD, Pascal. 2016: "Entre mer et rivière: les ports fluvio-maritimes de Méditerranée ancienne. Modèles et solutions". En C. SANCHEZ et M.-P. JEZEGOU (eds.): Les ports dans l'espace méditerranéen antique: Narbonne et les systèmes portuaires fluvio-lagunaires. Actes du colloque international de Montpellier (Montpellier 2014), pp. 139-156. Association de la Revue archéologique de Narbonnaise. Montpellier.

ARNAUD, Pascal. 2019: "Naviguer dans les détroits". En F. des BOSCS-PLATEAUX; Y. DEJUGNAT et A. HAUSHALTER (eds.): Le détroit de Gibraltar (Antiquité - Moyen Age). I. Représen- tations, perceptions, imaginaires (Casa de Velázquez 174), pp. 189-214. Casa de Velázquez. Madrid.

ARRUDA, Ana Margarida; BARROS, Pedro; LOPES, Virgílio. 1998: "As Cerâmicas áticas de Mértola". Conímbriga, 37, pp. 121-149.

BENQUET, Laurence. 2016: "Les amphores découvertes au domaine des Forges". En J.-M. FABRE; C. DOMERGUE et F. DABOSI (eds.): Le fer romain de la Montagne Noire. Martys 2: les débuts. 25 années de recherches pluridisciplinaires (1988-2013) (Revue Archéologique de Narbonnaise Supplément 43), pp. 216-230. Association de la Revue Archéologique de Narbonnaise. Montpellier.

BERNAL CASASOLA, Darío; DÍAZ RODRIGUEZ, José Juan; EXPÓSITO ALVAREZ, José Ángel; SÁEZ ROMERO, Antonio Manuel; LORENZO MARTINEZ, Lourdes; SÁEZ ROMERO, Antonio Manuel. 2003: Arqueología y Urbanismo. Avance de los hallazgos de época púnica y romana en las obras de la carretera de Camposoto (San Fernando, Cádiz). Cajasur. Jerez de la Frontera.

BERNAL CASASOLA, Darío; SÁEZ ROMERO, Antonio Manuel; LEGUPÍN TUBIO, Isaac. 2005: "Actividades industriales en las Villae Maritimae altoimperiales de la Bahia de Cadiz. Hallazgo de un lacus posiblemente relacionado con la industria textil en la calle Chile de San Fernando (Cádiz)". Caetaria: revista bianual de Arqueología, 4-5, pp. 97-114.

BERNAL CASASOLA, Darío; LARA MEDINA, Macarena; VARGAS GIRÓN, José Manuel. 2010: “Placas prefabricadas para parrillas de hornos en la plaza de Asdrúbal de Gadir/Gades". Ex Officina Hispana. Boletín de la SECAH, 2, pp. 31-34. BERNAL CASASOLA, Darío; SÁEZ ROMERO, Antonio Manuel; BUSTAMANTE ÁLVAREZ, Macarena. 2011: "Entre la pesca y la púrpura en el Gadir tardopúnico. Actuación arqueológica en el conchero de la C/ Luis Milena de San Fernando". En G. ALFARO; J.-P. BRUN; P. BORGARD y R. PIEROBON BENOIT (eds.): Textiles y tintes en la ciudad antigua. Actas del III Symposium internacional sobre textiles y tintes del Mediterráneo en el mundo antiguo 2008 (Nápoles 2008), pp. 157-180. Universitat de València. Valencia.

BERNAL CASASOLA, Darío; GARCÍA VARGAS, Enrique; SÁEZ ROMERO, Antonio Manuel. 2013: "Ánforas itálicas en la Hispania meridional". En G. OLCESE (ed.): Ricerche archeologiche, 
archeometriche e informatiche per la ricostruzione dell'economia e dei commerci nel bacino occidentale del Mediterraneo (metà IV sec. a.C. - I sec. d.C.), pp. 351-372. Edizioni Quasar. Roma.

BERNAL CASASOLA, Darío; GARCÍA VARGAS, Enrique. 2014: "Talleres haliéuticos en la Hispania romana". Anejos de Archivo Español de Arqueología, 71, pp. 295-318.

BERNAL CASASOLA, Darío; SÁEZ ROMERO, Antonio Manuel. 2019: "Garum y salazones de la Hispania Ulterior. Primeras identificaciones de ánforas de producción púnico-gaditana en Pompeya". En D. BERNAL CASASOLA y D. COTTICA (eds.): Scambi e commerci in area vesuviana. I dati delle anfore dai saggi stratigrafici I.E. (Impianto Elettrico) 1980-81 nel Foro di Pompei (Roman and Late Antique Mediterranean Pottery 14), pp. 96-116. Archaeopress. Oxford. Doi: $10.2307 /$ j.ctvwh8bxq.

BERNAL CASASOLA, Darío; VARGAS GIRÓN, José Manuel. 2019: "El Testaccio haliéutico de Gades". En D. BERNAL CASASOLA; J.M. VARGAS GIRÓN y LARA MEDINA M. (eds.): 7 metros de la Historia de Cádiz... Arqueología en El Olivillo y en el Colegio Mayor Universitario, p. 237-328. Servicios de Publicaciones de la Universidad de Cádiz. Cádiz.

BERNAL CASASOLA, Darío; COTTICA, Daniela. 2019: "Alcune riflessioni sui flussi di scambio a Pompei attraverso lo studio delle anfore dagli scavi I.E. del Foro". En D. BERNAL CASASOLA y D. COTTICA (eds.): Scambi e commerci in area vesuviana. I dati delle anfore dai saggi stratigrafici I.E. (Impianto Elettrico) 1980-81 nel Foro di Pompei (Roman and Late Antique Mediterranean Pottery 14), pp. 191-209. Archaeopress. Oxford. Doi: 10.2307/j.ctvwh8bxq.

BERNARD, Gwladys. 2018: Nec plus ultra: L'extrême Occident méditerranéen dans l'espace politique romain (218 av. J.-C. - 305 apr. J.-C.) (Bibliothèque de la Casa de Velázquez 72). Casa de Velázquez. Madrid.

BERROCAL-RANGEL, Luis. 2017: "Lusitanos, célticos y vettones, oponentes de Roma". En E. MARTÍNEZ RUIZ; J. CANTERA MONTENEGRO y M. de PAZZIS PI CORRALES (eds.): La guerra en el arte, pp. 61-81. Universidad Autónoma de Madrid. Madrid.

BOWMAN, Alan; WILSON, Andrew. 2009: "Quantifying the Roman Economy: Integration, Grow- th and Decline?". En A. BOWMAN y A. WILSON (eds.): Quantifying the Roman Economy. Methods and Problems, pp. 213-249. Oxford University Press. Oxford.

BRIDOUX, Virginie; KBIRI ALAOUI, Mohamed; ANDRÉ, Natalie; GRISONI, Emeline; ICHKHAKH, Abdelfatah; JULLIEN, Thierry; LENOIR, Eliane; NAJI, Halima. 2015: "Kouass (Asilah, Maroc)". Chronique des activités archéologiques de l'École française de Rome, Maghreb. http:// journals.openedition.org/cefr/1389.

CABRERA BONET, Paloma. 1997: "La presencia griega en Andalucía (siglos VI al IV a.C.)". En J. FERNÁNDEZ; C. GARCÍA y P. RUFETE (eds.): La Andalucía ibero-turdetana (siglos VI-IV a.C.) (Huelva Arqueológica XIV), pp. 367-390. Diputación Provincial de Huelva. Huelva.

CALLEGARIN, Laurent. 2000: Gadir-Gadès et le "circuit du Détroit" de la genèse à l'époque augustéenne. Trabajo de investigación de tercer Ciclo. Université de Toulouse 2-Le Mirail. Toulouse.

CARRERAS MONFORT, Cesar; MORAIS, Rui Roberto. 2012: "The Atlantic Roman trade during the Principate: new evidence from the western façade". Oxford Journal of Archaeology, 31 (4), p. 419-441. Doi: https://doi.org/10.1111/j.1468-0092.2012.00396.x.

CARRERAS MONFORT, Cesar; MARTIN MENENDEZ, Albert; PERA ISERN, Joaquim; RODRIGO REQUENA, Esther. 2017: "Las ánforas de Brindisi en Hispania Citerior. Pautas de distribución y consumo". SAGVNTVM, 48, pp. 103-121. Doi: $10.7203 /$ SAGVNTVM.48.7671.

CARRETERO POBLETE, Pedro Antonio. 2004: "Las producciones cerámicas de ánforas tipo 'Campamentos Numantinos' y su origen en San Fernando (Cádiz): los hornos de Pery Junquera". En L.G. LAGÓSTENA BARRIOS y D. BERNAL CASASOLA (eds.): Talleres Alfareros y producciones cerámicas en la Bética romana (ss. II a.C.-VII d.C.). Actas del Congreso Internacional de Figlinae Baeticae (Cádiz 2003), vol. 2, pp. 427-440. John \& Erika Hedges. Oxford.

CELESTINO PÉREZ, Sebastián; GRACIA ALONSO, Francisco; RODRÍGUEZ GONZÁLEZ, Esther. 2017: "Copas para un banquete. La distribución de cerámicas áticas en Extremadura". En X. AQUILUE; P. CABRERA y M. ORFILA (eds.): Homenaje a Gloria Trías Rubiés. Cerámicas griegas de la Península Ibérica: cincuenta años después (1967-2017), pp. 140-149. Centro Ibe- 
ria Graeca. Barcelona.

CHIC GARCÍA, Genaro. 2004: "La gaditanización de Hispania". XVI Encuentros de Historia y Arqueología. Las industrias alfareras y conserveras fenicio-púnicas de la Bahía de Cádiz (San Fernando 2000), pp. 39-62. Publicaciones Obra Social y Cultural CajaSur. Córdoba.

CHIC GARCÍA, Genaro. 2004: "La gaditanización de Hispania". XVI Encuentros de Historia y Arqueología. Las industrias alfareras y conserveras fenicio-púnicas de la Bahía de Cádiz. (San Fernando 2000), pp. 39-62. Publicaciones Obra Social y Cultural CajaSur. Córdoba.

COLTELLONI-TRANNOY, Michèle; BRIDOUX, Virginie; BROUQUIER-REDDÉ, Véronique (eds.). 2016: "Le cercle du Détroit dans l'Antiquité: l'héritage de Miguel Tarradell". Karthago: Revue d'archéologie méditerranéenne, 29.

CRUZ ANDREOTTI, Gonzalo. 1994: "La visión geográfica de Gades en Estrabón: la elaboración de un paradigma geográfico". Dialogues d'Histoire Ancienne, 20 (1), pp. 57-85.

DES BOSCS-PLATEAUX, Françoise. 1994: "L. Cornelius Balbus de Gadès: la carrière méconnue d'un Espagnol à l'époque des guerres civiles (Ier siècle av. J.-C.)". Mélanges de la Casa de Velázquez, 30 (1), pp. 7-35. Doi: 10.3406/ casa.1994.2678.

DES BOSCS-PLATEAUX, Françoise. 2005: Un parti hispanique à Rome? Ascension des élites hispaniques et pouvoir politique d'Auguste à Hadrien (27 av. J.-C. - 138 ap. J.-C.). Casa de Velázquez. Madrid.

DES BOSCS-PLATEAUX, Françoise. 2014: "Les transformations économiques de la péninsule Ibérique (70 av. J.-C.-73 apr. J.-C.): productions et structures". Pallas, 96, pp. 167-192. Doi: https://doi.org/10.4000/pallas.1234.

DÍAZ GARCÍA, Moisés. 2016: "Las ánforas de Tarraco de los siglos II y I a.C.". En R. JÁRREGA y P. BERNI (eds.): Actas del III Congreso Internacional de la Sociedad de Estudios de la Cerámica Antigua (SECAH). Amphorae ex Hispania: paisajes de producción y consumo (Tarragona 2014), pp. 163-182. Instituto Catalán de Arqueología Clásica. Tarragona.

DÍAZ RODRÍGUEZ, José Juan; SÁEZ ROMERO, Antonio Manuel. 2010: "Gallineras - Cerro de los Mártires". En R. HIDALGO (ed): Las villas romanas de la Bética, vol. 2, pp. 94-107. Editorial Universidad de Sevilla. Sevilla.

DIOS BORREGO DE LA PAZ, Juan de. 2011: “La con- figuración arquitectónica del Teatro Romano de Cádiz: nuevas perspectivas". En D. BERNAL y A. ARÉVALO (eds.): Theatrum Balbi de Gades: actas del Seminario 'El Teatro Romano de Gades, una Mirada al Futuro' (Cádiz 2009), pp. 171-226. Servicio de Publicaciones de la Universidad de Cádiz. Cádiz.

DOMERGUE, Claude. 2004: "Le régime juridique des mines du domaine public à Rome. À propos d'un ouvrage récent". Mélanges de la Casa de Velázquez, 34 (2), pp. 221-236. Doi: https://doi.org/10.4000/mcv.1343.

DOMÍNGUEZ PÉREZ, Juan Carlos (eds.). 2011: Gadiry el Círculo del Estrecho revisados: propuestas de la arqueología desde un enfoque social. Servicio de Publicaciones de la Universidad de Cádiz. Cádiz.

ESCACENA CARRASCO, José Luis; MORENO MEGIAS, Violeta. 2014: “Cerámica de tipo Kuass procedente de Caura. ¿Testimonios de un nuevo centro de producción?". Archivo Español De Arqueología, 87, pp. 75-90. Doi: https://doi. org/10.3989/aespa.087.014.005.

FANTUZZI, Leandro; KIRIATZI, Evangelia; SÁEZ ROMERO, Antonio Manuel; MÜLLER, Noémi Suzanne; WILLIAMS, Charles. 2020: "Punic amphorae found at Corinth: provenance analysis and implications for the study of long-distance salt fish trade in the Classical period". Archaeological and Anthropological Sciences, 12 (8), pp. 179.

FERREIRA, Daniela. 2020: "Cerâmica grega no norte de Portugal”. En E. FERRER (ed.): La ruta de las Estrímnides. Navegación y conocimiento del litoral atlántico de Iberia en la Antigüedad, pp. 521-548. Universidad de Alcalá de Henares. Alcalá de Henares.

FERRER ALBELDA, Eduardo. 2004: "Sustratos fenicios y adstratos púnicos: los bástulos entre el Guadiana y el Guadalquivir". Huelva Arqueológica, 20, pp. 281-298.

FERRER ALBELDA, Eduardo; GARCÍA FERNÁNDEZ, Francisco José; SÁEZ ROMERO, Antonio Manuel; RODRÍGUEZ-CORRAL, Javier; ALBUQUERQUE, Pedro. 2019: "Rota do Estanho: Gadir e o Comércio Fenício no Noroeste da Ibéria (Séculos IV - II a.C.)/ The Route of the Tin: Gadir and the Phoenician Trade in the Northwest of Iberia (4th-2nd centuries BC)". Hélade, 5 (2), pp. 83-151. Doi: https://doi. org/10.22409/rh.v5i2.42485.

FERREIRO LÓPEZ, Manuel. 2008: "Cádiz en el 
tiempo de los César y los Balbo. La ordenación territorial en la Bahía de Cádiz a finales de la Republica romana". Revista Atlántica-Mediterránea de Prehistoria y Arqueología Social, 10, pp. 309-324.

FRUTOS REYES, Gregorio De; MUÑOZ VICENTE, Ángel. 1996: "La industria pesquera y conservera púnico-gaditana: Balance de la investigación. Nuevas perspectivas". Spal, 5, pp. 133165. Doi: $10.12795 /$ spal.1996.i5.07.

GARCÍA FERNÁNDEZ, Francisco José. 2019a: "Rumbo a poniente: el comercio de ánforas turdetanas en la costa atlántica de la Península Ibérica (siglos V-I a. C.)". Archivo Español De Arqueología, 92, pp. 119-153. Doi: https://doi. org/10.3989/aespa.092.019.007.

GARCÍA FERNÁNDEZ, Francisco José; GARCÍA VARGAS, Enrique. 2010: "Entre gaditanización y romanización: repertorios cerámicos, alimentación e integración cultural en Turdetania (siglos III-I a.C.)". SAGVNTVM, Extra-9, pp. 116-135.

GARCÍA VARGAS, Enrique. 1996: “La producción anfórica en la Bahía de Cádiz durante la República como índice de romanización". Habis, 27, pp. 49-62. Doi: 10.12795/Habis.1996.i27.05.

GARCÍA VARGAS, Enrique. 1998: La producción de ánforas en la bahía de Cádiz en época romana: (siglos II A.C-IV D.C.). Gráficas Sol. Écija.

GARCÍA VARGAS, Enrique. 2008: "Entre el consumo de lujo y el gusto popular: las salazones de la Iberia púnica y su romanización (siglos V-I a.C.). Una perspectiva histórica y cultural". En J. NAPOLI (ed.): Actes du colloque international Ressources et activités maritimes des peuples de l'antiquité (Boulogne-sur-Mer 2005), pp. 87-108. Centre de Recherche en Histoire Atlantique et Littorale. Boulogne-sur-Mer.

GARCÍA VARGAS, Enrique. 2019b: "Economy and Romanization of Hispania Ulterior". En G. CRUZ ANDREOTTI (ed.): Roman Turdetania. Romanization, Identity and Socio-Cultural Interaction in the South of the Iberian Peninsula between the 4th and 1st Centuries BCE (Cultural Interactions in the Mediterranean 3), pp. 164-185. Brill. Leiden.

GARCÍA VARGAS, Enrique; ALMEIDA, Rui Roberto; GONZÁLEZ CESTEROS, Horacio. 2011: "Los tipos anfóricos del Guadalquivir en el marco de los envases sudhíspanos del siglo I a.C. Un universo heterogéneo entre la imitación y la estandarización". Spal, 20, pp. 185-283. Doi: 10.12795/spal.2011.i20.12.

GARCÍA VARGAS, Enrique; SÁEZ ROMERO, Antonio Manuel. 2018: "Todo el pescado vendido. Una lectura cuantitativa de la producción púnica y romana de ánforas, sal y salazones en la Bahía de Cádiz". En J. REMESAL; V. REVILLA y J.M. BERMUDEZ (eds.): Cuantificar las economías antiguas: Problemas y métodos, pp. 161-214. Universidad de Barcelona. Barcelona.

GARCÍA VARGAS, Enrique; DE ALMEIDA, Rui Roberto; GONZALEZ, Horacio; SÁEZ ROMERO, Antonio Manuel (eds.). 2019: The Ovoid Amphorae in the Central and Western Mediterranean. Between the last two centuries of the Republic and the early days of the Empire. Archaeopress. Oxford.

GIRARD, Sylvie. 1984: "Banasa Préromaine. Un état de la question". Antiquités africaines, 20, pp. 11-93.

GOMES, Francisco. 2017: “Un conjunto de cerámicas áticas inéditas de la necrópolis de Olival do Senhor dos Mártires (Alcácer do Sal, Portugal)". Onoba, 5, pp. 45-58.

GONZÁLEZ CESTEROS, Horacio; GARCÍA VARGAS, Enrique; ALMEIDA, Rui Roberto. 2018: "Análisis de caso: las ánforas ovoides de la Hispania Tardorrepublicana". Ex Officina Hispana: cuadernos de la SECAH, 3, pp. 81-112.

GONZÁLEZ TORAYA, Beatriz; TORRES QUIRÓS, José; LAGÓSTENA BARRIOS, Lazaro Gabriel; PRIETO REINA, Óscar. 2002: "Los inicios de la producción anfórica en la bahía gaditana en época republicana: la intervención de urgencia en Avda. Pery Junquera (San Fernando, Cádiz)". En G. CHIC GARCÍA (ed.): Conservas, aceite y vino de la Bética en el Imperio Romano. Actas del Congreso internacional de Sevilla y Écija Ex Baetica Amphorae (Écija 1998), vol. 1, pp. 175-186. Gráficas Sol. Écija.

GOZALBES CRAVIOTO, Enrique. 2016: "El Círculo del Estrecho en la Antigüedad. Una revisión historiográfica". Índice Histórico Español, 128, pp. 175-209.

GREGORATTI, Leonardo. 2015: "Roman Traders as a Factor of Romanization in Noricum and in the Eastern Transalpine Region". En S.T. ROSELAAR (ed.): Processes of cultural change and integration in the Roman world, p. 239-252. Brill. Leiden.

HASSINI, Hicham. 2006: "Le Maroc et l'Espagne à l"époque antique. Échanges commerciaux ou marché commun?". En A. AKERRAZ et (eds.): 
L'Africa romana. XVI Convegno Internazionale di Studi. Mobilità delle persone e dei popoli, dinamiche migratorie, emigrazioni ed immigrazioi nelle province occidentali dell'Imperio romano (Rabat 2004), vol. 2, pp. 803-812. Publicazioni del Dipartimento di Storia dell'Università di Sassari-Carocci. Roma.

HERAS MORA, Francisco Javier; BUSTAMANTE ÁLVAREZ, Macarena. 2007: "Contribución al estudio de las ánforas tardorrepublicanas del enclave militar de El Santo de Valdetorres". Vipasca. Arqueología e Historia, 2 (2), pp. 318324.

HOLLANDER, David. 2007: Money in the late Roman Republic. Brill. Leiden.

JIMÉNEZ ÁVILA, Javier. 2017: "Los estudios sobre cerámica griega en Extremadura". En X. AQUILUE; P. CABRERA y M. ORFILA (eds.): Homenaje a Gloria Trías Rubiés. Cerámicas griegas de la Península Ibérica: cincuenta años después (1967-2017), pp. 234-245. Centro Iberia Graeca. Barcelona.

KBIRI ALAOUI, Mohamed. 2006: "Marruecos púnico: historia y desarrollo de la investigación arqueológica". En D. BERNA; B. RAISSOUNI; J. RAMOS y A. BOUZOUGGAR (eds.): Actas del I seminario Hispano-Marroquí de especialización en arqueología (Cádiz 2005), pp. 145-155. Universidad de Cádiz y Universidad Abdelmalek Esadi de Tetuán. Cádiz-Tetuán.

KBIRI ALAOUI, Mohamed. 2007: "Kuass (Asilah, Marruecos). Alfarería y economía (ss. V-I A.C)". SAGVNTVM, Extra-7, pp. 13-28.

LAMBOGLIA, Nino. 1955: "Sulla cronologia delle anfore romanedi età republicana (II-I secolo A.C.)" Rivista di Studi Liguri, 21, pp. 241-270.

LAGOSTENA BARRIOS, Lázaro Gabriel; BERNAL CASASOLA, Darío. 2004: "Alfares y producciones cerámicas en la provincia de Cádiz: Balance y perspectivas". En L.G. LAGÓSTENA BARRIOS y D. BERNAL CASASOLA (eds.): $T a-$ lleres Alfareros y producciones cerámicas en la Bética romana (ss. II a.C.-VII d.C.). Actas del Congreso Internacional de Figlinae Baeticae (Cádiz 2003), vol. 2, pp. 39-124. John \& Erika Hedges. Oxford.

LARA MEDINA, Macarena. 2018: "Sobre el abastecimiento, la distribución y la evacuación hídrica en Gades". Zephyrus, LXXI, pp. 141-163.

LE ROUX, Patrick. 2004: "La romanisation en question”. Annales. Histoire, Sciences Sociales, 59 (2), pp. 287-311.
LIOU, Bernard. 2000: "Las ánforas béticas en el mar". En D. BERNAL y E. GARCÍA (eds.): Actas del Congreso internacional Ex Baetica Amphorae. Conservas, aceite y vino de la Bética en el imperio romano (Sevilla-Écija 1998), pp. 10611110. Graficas Sol. Écija.

LÓPEZ CASTRO, José Luis. 1991: "El Foedus de Gadir del 206 a.C.: una revisión". Florentia Iliberritana, 2, pp. 269-280.

LÓPEZ JURADO, Reyes; SÁEZ ROMERO, Antonio. 2020: "A propósito de un sello inédito sobre un ánfora Dressel 1 itálica encontrada en el Cerro de los Mártires (San Fernando, Cádiz)". Habis, 51, pp. 87-106. Doi: http://dx.doi. org/10.12795/Habis.2020.i51.06.

LÓPEZ PARDO, Fernando. 2008: "Marinos y colonos fenicios codificando la costa atlántica africana". En J.M. CANDAU; F.J. GONZALEZ y A.L. CHAVEZ (eds.): Libyae lustrare extrema. Realidad y literatura en la visión grecorromana de África. Homenaje al Prof. Jehan Desanges, pp. 25-51. Universidad de Sevilla. Sevilla.

LÓPEZ ROSENDO, Ester. 2008: "El alfar romano altoimperial del Jardín de Cano (El Puerto de Santa María, Cádiz. España), en el contexto económico de Gades". Revista de Historia de El Puerto, 41, pp. 39-74.

LOUGHTON, Matthew. 2016: "Punic amphorae from Toulouse 'caserne Niel' (Haute-Garonne, Fr.) ". En D. DJAOUI (ed.): Histoires matérielles: terre cuite, bois, métal et autres objets. Des pots et des potes: Mélanges offerts à Lucien Rivet, pp. 431-437. Mergoil. Montagnac.

LUACES, Max. 2016. "Nuevos datos sobre la difusión de las ánforas tardopúnicas hispanas: algunos casos de estudio franceses". En R. JÁRREGA y P. BERNI (eds.): Actas del III Congreso Internacional de la Sociedad de Estudios de la Cerámica Antigua (SECAH). Amphorae ex Hispania: paisajes de producción y consumo (Tarragona 2014), pp. 699-712. Instituto Catalán de Arqueología Clásica. Tarragona.

LUACES, Max. 2019. "Les anciennes communautés phéniciennes du détroit de Gibraltar face à Rome". En L. BONADIES, I. CHIRPANLIEVA et E. GUILLON (eds): Les Phéniciens, les Puniques et les autres. Echanges et identités en Méditerranée ancienne, pp 281-302. De Boccard. Paris.

LUACES, Max. 2020. "Les relations entre le Cercle du Détroit et le monde romain (206-44 av. J.C.): un cadre interprétatif à nuancer ?" En S. 
CELESTINO y E. RODRIGUEZ (eds.): Un viaje entre el Oriente y el Occidente del Mediterráneo. Actas del IX Congreso Internacional de Estudios Fenicios y Púnicos (Mérida 2018), pp. 763-775. Instituto de Arqueología de Mérida. Mérida.

LUACES, Max; SAEZ ROMERO, Antonio Manuel. 2019: “Late Punic amphorae in 'Roman' shipwrecks of southern Gaul: the evidence of a trading route from the Atlantic and the Strait of Gibraltar region to the Tyrrhenian Sea". En A. PEIGNARD (dir.): Daily life in a cosmopolitan world: pottery and culture during the Hellenistic period. Proceedings of the second IARPotHP International Conference (Lyon 2015), pp. 143157. Phoibos Verlag, Vienna.

MACMULLEN, Ramsay. 2003: La romanisation à l'époque d'Auguste. Les Belles Lettres. Paris.

MARIA JAIA, Alessandro; DOMINICIS, Danilo de. 2020: "La circolazione delle anfore puniche nell'area laziale e nell'Etruria meridionale". En S. CELESTINO y E. RODRIGUEZ (eds.): Un viaje entre el Oriente y el Occidente del Mediterráneo. Actas del IX Congreso Internacional de Estudios Fenicios y Púnicos (Mérida 2018), pp. 751-761. Instituto de Arqueología de Mérida. Mérida.

MARTÍN I OLIVERAS, Antoni; MARTÍN-ARROYO SÁNCHEZ, Daniel; REVILLA CALVO, Victor 2017: "The wine economy in Roman Hispania. Archaeological data and modelization". En J. REMESAL (ed.): Economía romana. Nuevas perspectivas/ The Roman economy. New perspectives, pp. 189-237. Universitat de Barcelona. Barcelona.

MATEO CORREDOR, Daniel. 2016: Comercio anfórico y relaciones mercantiles en Hispania Ulterior (s. II a.C. - II d.C.) (Instrumenta 52). Universitat de Barcelona. Barcelona.

MEDEROS MARTIN, Alfredo. 2006: "El periplo norteafricano de Ofelas". Gerión, 24 (1), pp. 65-84.

MEDEROS MARTIN, Alfredo. 2015: "La exploración del litoral atlántico norteafricano según el periplo de Hannón de Cartago". Gerión, 33, pp. 15-45.

MEDEROS MARTIN, Alfredo; ESCRIBANO COBO, Gabriel. 2000: "El periplo norteafricano de Hannón y la rivalidad gaditano-cartaginesa de los siglos IV-III a.C.". Gerión, 18, pp. 77-107.

MEDEROS MARTIN, Alfredo; ESCRIBANO COBO, Gabriel. 2004: "Los periplos de Eudoxo de Cízico en la Mauretania Atlántica". Gerión, 22
(1), pp. 215-233.

MEDEROS MARTIN, Alfredo; ESCRIBANO COBO, Gabriel. 2015: Oceanus gaditanus: oro, púrpura y pesca en el litoral atlántico norteafricano y las Islas Canarias en época fenicia, cartaginesa y romana republicana. Ediciones Idea. Santa Cruz de Tenerife.

MOLINA VIDAL, Jaime. 1997: La dinámica comercial romana entre Italia e Hispania Citerior (siglos II a.C.-II d.C.). Universidad de Alicante. Alicante.

MORAIS, Rui. 2007: "A via atlântica e o contributo de Gádir nas campanhas romanas na fachada noroeste da península". Humanitas, 59, pp. 99132.

MORENO MEGIAS, Violeta. 2016: La influencia púnica en las mesas turdetanas: Cerámica de tipo Kuass en el Bajo Valle del Guadalquivir (Monografías de Archivo Hispalense. Historia 76). Servicio de Archivo y Publicaciones de la Diputación de Sevilla. Sevilla.

MORET, Pierre. 2012: "Artemidoro y la ordenación territorial de Hispania en época republicana". En J. SANTOS; G. CRUZ; M. FERNANDEZ y L. SANCHEZ (eds): Romanización, fronteras y etnias en la Roma antigua: el caso hispano (Revisiones de Historia Antigua 7), pp. 425-456. Universidad del País Vasco. Vitoria.

MUÑOZ VICENTE, Ángel. 1997: “Secuencia histórica del asentamiento fenicio-púnico de Cádiz: un análisis crono-espacial tras quince años de investigación arqueológica". Boletín del Museo de Cádiz, 1995/7, pp. 77-105.

MUÑOZ VICENTE, Ángel. 2008: "Topografía y ritual en la necrópolis fenicio-púnica de Cádiz". En F.J. GUZMÁN y V. CASTAÑEDA, (eds.): Vida y Muerte en la Historia de Cádiz, pp. 57-84. Cemabasa. Cádiz.

MUÑOZ VICENTE, Ángel; FRUTOS REYES, Gregorio de; BERRIATUA, Nerea. 1988: “Contribución a los orígenes y difusión comercial de la industria pesquera y conservera gaditana a través de las recientes aportaciones de las factorías de salazones de la Bahía de Cádiz". Congreso Internacional El Estrecho de Gibraltar (Ceuta 1987), vol. 1, pp. 487-508. Madrid

MURCIA MUÑOZ, Antonio Javier; RUIZ VALDERAS, Elena; RAMALLO ASENSIO Sebastián. 2013: "La reestructuración del sistema defensivo a finales de la República: los rellenos constructivos de la muralla del siglo I a.C. (Cerro de la Concepción, Cartagena)". Anales de prehistoria 
y arqueología, 29, pp. 103-130. Doi: http:// hdl.handle.net/10201/77085.

NIVEAU DE VILLEDARY, Ana María. 2001: “El espacio geopolítico gaditano en época púnica. Revisión y puesta al día del concepto de 'Círculo del Estrecho'”. Gerión, 19, pp. 313-354.

NIVEAU DE VILLEDARY, Ana María. 2004: "La producción de barniz púnico-gaditano en el s. II a.C. Nuevos datos aportados por Nuevos datos aportados por el conjunto alfarero de Pery Junquera (San Fernando, Cádiz)". En L.G. LAGÓSTENA y D. BERNAL (eds.): Talleres Alfareros y producciones cerámicas en la Bética romana (ss. II a.C.-VII d.C.). Actas del Congreso Internacional de Figlinae Baeticae (Cádiz 2003), vol. 2, pp. 677-690. John et Erika Hedges. Oxford.

NIVEAU DE VILLEDARY, Ana María. 2009: Ofrendas, banquetes y libaciones. El ritual funerario en la necrópolis púnica de Cádiz. Secretario de publicaciones Universidad de Sevilla. Sevilla.

NIVEAU DE VILLEDARY, Ana María; SAEZ ROMERO, Antonio Manuel. 2016: "The Red Slip Tableware of Punic and Early Roman Gadir/ Gades (4th and 1st cent. BC): An Update on the so-called 'Kuass Ware'”. En S. JAPP y P. KÖGLER (eds.): Traditions and Innovations. Tracking the Development of Pottery from the Late Classical to the Early Imperials Periods. IARPotHP Proceedings 1, pp. 55-68. Phoibos Verlag. Wien.

NIVEAU DE VILLEDARY, Ana María; VALLEJO SANCHEZ, Juan Ignacio. 2000: “Evolución y estructura del comercio gaditano en época púnica. Un avance a partir de la documentación arqueológica I (ss. VI-IV a.n.e.)". En P. FERNÁNDEZ; C. GONZÁLEZ y F. LÓPEZ (eds.): Intercambio preclásico en el Mediterráneo. Actas del I Coloquio del Centro de Estudios Fenicios y Púnicos (Madrid 1998), pp. 313-338. Centro de Estudios Fenicios y Púnicos. Madrid.

PELLICER CATALAN, Manuel; BENDALA GALAN, Manuel; ESCACENA CARRASCO, José Luis. 1983: El Cerro Macareno. Ministerio de Educación y Ciencia. Madrid

PÉREZ MACÍAS, Juan Aurelio; DELGADO DOMÍNGUEZ, Aquilino. 2011: "El castellum de El Castillejo (El Campillo, Huelva): la explotación romano-republicana en Riotinto". En J.A. PÉREZ; A. DELGADO; J.M. PÉREZ y F.J. GARCÍA (eds.): Río Tinto: Historia, Patrimonio Minero y Turismo Cultural, pp. 47-73. Servicio de Publicacio- nes Universidad de Huelva. Huelva.

PÉREZ-MALUMBRES LANDA, A. 2012: "Contextos comerciales de la transición de la 'Malaka' fenicia a la romana en los solares de calle Granada, 57-61". En B. MORA y G. CRUZ (eds.): $L a$ etapa neopúnica en Hispania y el Mediterráneo centro occidental: identidades compartidas, pp. 361-390. Editorial de la Universidad de Sevilla. Sevilla.

PONS PUJOL, Lluís. 2015: "La invención de un concepto geopolítico: el Estrecho de Gibraltar en la Antigüedad". Scripta Nova: revista electrónica de geografía y ciencias sociales, 19. https:// www.raco.cat/index.php/ScriptaNova/article/view/298220.

PONSICH, Michel. 1969: "Alfarerías de época fenicia y púnico-mauritana en Kuass (Arcila, Marruecos)". Papeles del Laboratorio de Arqueología de Valencia, 4, pp. 3-25.

PONSICH, Michel. 1975: "Pérennité des relations dans le circuit du Détroit de Gibraltar". En H. TEMPORINI (ed.): Aufstieg und Niedergang der römischen Welt (Politische Geschichte. Provinzen und Randvölker 3), pp. 654-684. Walter de Gruyter. Berlin. Doi: https://doi. org/10.1515/9783110882070-018.

QUILLON, Kévin. 2016: Les amphores à salaisons et sauces de poissons de Bétique et de Tarraconaise: typologie et contenu (fin de la République - Haut-Empire). Trabajo de investigación de tercer Ciclo. Université d'Aix Marseille. Aix-en-Provence.

QUILLON, Kévin; CAPELLI, Claudio. 2016: “Les amphores de l'épave du Titan: typologie, origine et contenu des Dressel 12A et des conteneurs du type 'Titan'". En R. JÁRREGA y P. BERNI (eds.): Actas del III Congreso Internacional de la Sociedad de Estudios de la Cerámica Antigua (SECAH). Amphorae ex Hispania: paisajes de producción y consumo (Tarragona 2014), pp. 491-497. Instituto Catalán de Arqueología Clásica. Tarragona.

QUILLON, Kévin; LUACES, Max. 2019: “Distribution of Gaditan and other Hispanic ovoid in Gaul during Late-Republican and Early Empire Times: trade routes and consumption contexts". En E. GARCÍA; R. DE ALMEIDA; H. GONZÁLEZ y A.M. SÁEZ (eds.): The Ovoid Amphorae in the Central and Western Mediterranean. Between the last two centuries of the Republic and the early days of the Roman Empire (Roman and Late Antique Mediterranean Pottery series 13), 
pp. 298-313. Archaeopress. Oxford.

RAMÓN TORRES, Joan. 1995: Las ánforas fenicio-púnicas del mediterráneo central y occidental (Instrumenta 2). Universitat de Barcelona. Barcelona.

RAMÓN TORRES, Joan. 2004: "La producción anfórica gaditana en época fenicio-púnica”. Las industrias alfareras y conserveras fenicio-púnicas de la Bahía de Cádiz. Actas de los XVI Encuentros de Historia y Arqueología de San Fernando 2000 (San Fernando 2000), pp. 63-100. Publicaciones Obra Social y Cultural CajaSur. Córdoba.

RAMÓN TORRES, Joan. 2008: "El comercio púnico en occidente en época tardorrepublicana (siglos -II/-I): Una perspectiva actual según el tráfico de productos envasados en ánforas". En J. UROZ; J.M. NOGUERA y F. COARELLI (eds.): Iberia e Italia: modelos romanos de integración territorial. Actas del IV Congreso Hispano-Italiano de Murcia (Murcia 2006), pp. 67-100. Tabularium. Murcia.

RAMON TORRES, Joan; SÁEZ ESPLIGARES, Antonio; SÁEZ ROMERO, Antonio; MUÑOZ VICENTE, Ángel. 2007: El taller alfarero tardoarcaico de Camposoto (Monografías de Arqueología 26). Junta de Andalucía. Sevilla.

RIBERA I LACOMBA, Albert. 1982: Las ánforas prerromanas valencianas (fenicias, ibéricas y púnicas). Diputación Provincial de Valencia. Valencia.

RIBERA LACOMBA, Albert. 1998: La fundació de Valentia. La ciutat a l'època romanorepublicana (segles II-I a. de C.) (Estudios Universitarios 71). Institució Alfons el Magnànim, Diputació de València. Valencia.

RIZZO, Giorgio; MORENO MEGIAS, Violeta. 2019: "Roma e le prime importazioni di alimenti ispanici trasportati in anfora". Journal of Roman Archaeology, 32, pp. 23-38. Doi: 10.1017/ S1047759419000047.

ROMAN, Yves. 2009: "Entre Rome et les Gaules, le commerce, vecteur de romanisation". Pallas, 80, pp. 245-277. Doi: https://doi. org/10.4000/pallas.1842.

RUFETE TOMICO, Pilar. 2002: El final de Tartessos y el periodo turdetano en Huelva. Huelva Arqueológica, 17, 3-204.

RUIZ GUTIERREZ, Alicia. 2009: "Les espaces économiques de la péninsule Ibérique à l'époque romaine (197 av. J.-C.- 192 apr. J.-C.)“. Pallas, 80, pp. 223-243. doi: 10.4000/pallas.1834.
SÁEZ ROMERO, Antonio Manuel. 2008: "La producción de ánforas en el área del Estrecho en época tardopúnica (siglos III-I a.C.)”. En D. BERNAL y A. RIBERA (eds.): Cerámicas hispanorromanas: un estado de la cuestión. Actas del XXVI Congreso Internacional de la Asociciòn Rei Cretariae Romanae Fautores (Cádiz 2008), pp. 635-659. Servicio de publicaciones Universidad de Cádiz. Cádiz.

SÁEZ ROMERO, Antonio Manuel. 2010: "La producción alfarera y la economía salazonera de Gadir: balance y novedades". Mainake, 32 (2), pp. 885-932.

SÁEZ ROMERO, Antonio Manuel. 2011: "El alfar tardopúnico de Torre Alta. Balance y estado de la cuestión tras veinte años de investigaciones". En J.J. DÍAZ; A.M. SÁEZ; E. VIJANDE y J. LAGÓSTENA (eds.): Actas de las Jornadas de Jóvenes Investigadores Prehistoria et Arqueología 2008. Estudios recientes de Arqueología Gaditana (Cádiz 2008), pp. 183-202. Archaeopress. Oxford.

SÁEZ ROMERO, Antonio Manuel. 2013: “Talleres cerámicos en Gadir en época postcolonial ¿un modelo alfarero excepcional?". En D. BERNAL; L.C. JUAN; M. BUSTAMANTE; J.J. DÍAZ y A.M. SÁEZ (eds.): I Congreso Internacional de SECAH, Ex Officina Hispana. Hornos, talleres y focos de producción alfarera en Hispania (Cádiz 2011), vol. 1, pp. 215-249. Servicio de Publicaciones de la Universidad de Cádiz. Cádiz.

SÁEZ ROMERO, Antonio Manuel. 2014: "Estudio de las ánforas de un pecio inédito de época púnica de la costa de Málaga". En F.X. NIETO y M. BETHENCOURT (eds.): Arqueología subacuática española: Actas del I Congreso de Arqueología Náutica y Subacuática Española, pp. 43-52. Universidad de Cádiz. Cádiz.

SÁEZ ROMERO, Antonio Manuel. 2018: "Apuntes sobre las dinámicas comerciales de Gadir entre los siglos VI y III a.C.". Gerión, 36 (1), pp. 1140. doi: https://doi.org/10.5209/GERI.60292 SÁEZ ROMERO, Antonio Manuel; DÍAZ RODRÍGUEZ, José Juan; SÁEZ ESPLIGARES, Antonio. 2005: "Nuevas aportaciones a la definición del Círculo del Estrecho: La cultura material a través de algunos centros alfareros". Gerión, 22 (1), pp. 31-60.

SÁEZ ROMERO, Antonio Manuel; DÍAZ RODRÍGUEZ, José Juan. 2010: “La otra necrópolis de Gadir/Gades: Enterramientos asociados a talleres alfareros en su hinterland insular". En 
A.M. NIVEAU y V. GÓMEZ (eds.): Las necrópolis de Cádiz. Apuntes de arqueología gaditana en homenaje a FJ. Sibón Olano, pp. 251-337. Servicio de publicaciones Universidad de Cádiz. Cádiz.

SAEZ ROMERO, Antonio Manuel; LUACES, Max. 2014: "Una posible ovoide gaditana en la rada de Marsella (Francia). Boletín Ex Officina Hispana, 5, pp. 39-41.

SÁEZ ROMERO, Antonio Manuel; LUACES, Max; MORENO PULIDO, Elena. 2016: "Late Punic or Early Roman? A 2nd century BC deposit from Gadir/Gades (Cadiz Bay, Spain)". HEROM. Journal on Hellenistic and Roman Material Culture, 5 (1), pp. 25-75.

SÁEZ ROMERO, Antonio Manuel; HIGUERAS-MILENA CASTELLANO, Aurora. 2016: "Nuevas investigaciones arqueológicas subacuáticas en el área de La Caleta (Cádiz, España). Estudio de las evidencias de época púnica (siglos VI-III a.C)". Lucentum, 35, pp. 9-41.

SÁEZ ROMERO, Antonio Manuel; FERRER ALBELDA, Eduardo. 2018: "Dioses de barro. Sellos con simbología religiosa de la producción anfórica de Gadir (siglos IV-II a.C.)". En A.D. NAVARRO y E. FERRER (eds.): Trabajo sagrado. Producción y representación en el Mediterráneo occidental durante el I milenio a.C., pp. 271-308. Editorial de la Universidad de Sevilla. Sevilla.

SÁEZ ROMERO, Antonio Manuel; CARRERO RAMÍREZ, Francisco. 2018: "Coto de la isleta (Chiclana, Cádiz). Nuevos datos y perspectivas sobre el poblamiento romano de la zona sur de la Bahía de Cádiz". Spal, 27 (1), pp. 185210. Doi: $10.12795 /$ spal.2018i27.07.

SÁEZ ROMERO, Antonio Manuel; BELIZÓN ARAGÓN, Ricardo. 2018: "Nuevos datos de los talleres cerámicos insulares de la Gadir púnica. Resultados preliminares de recientes excavaciones en el entorno de Villa Maruja - Polígono Janer (San Fernando, Cádiz)". Folia Phoenicia 2, pp. 194-204. Doi: 10.19272/201813201028.

SAEZ ROMERO, Antonio Manuel; LUACES, Max. 2019: "Trading like a Roman? Roman amphorae imitations in the Strait of Gibraltar region during the late Republican period (3rd-1st c. BC)". En A. PEIGNARD (ed.): Daily life in a cosmopolitan world: pottery and culture during the Hellenistic period. Proceedings of the second IARPotHP International Conference, (Lyon 2015), pp. 131-142. Phoibos Verlag.
Vienna.

SAEZ ROMERO, Antonio Manuel; LAVADO FLORID0, María Luisa. 2019: “Cremaciones fenicias y un nuevo saladero de pes $\neg$ cado púnico de Gadir. Avance de los hallazgos registrados en el área de Los Chinchorros (Calle San Bartolomé, Cádiz)". Habis, 50, pp. 49-81.

SÁEZ ROMERO, Antonio Manuel; GUTIERREZ LOPEZ, José María; REINOSO DEL RIO, María Cristina. 2020: "Un asentamiento de época púnica en la campiña costera de la Bahía de Cádiz: Estructuras, fases de uso y contextos materiales de Puerto-19". Archivo español de arqueología, 93, pp. 61-80. Doi: https://doi. org/10.3989/aespa.093.020.003.

SÁEZ ROMERO, Antonio Manuel; GARCÍA FERNÁNDEZ, Francisco José; FERRER ALBELDA, Eduardo; RODRÍGUEZ CORRAL, Javier; REY, Josefa. 2020: "Proyecto Estrímnides: resultados preliminares". En E. FERRER (ed.): La ruta de las Estrímnides. Navegación y conocimiento del litoral atlántico de Iberia en la Antigüedad, pp. 567-648. Universidad de Alcalá de Henares. Alcalá de Henares.

SÁEZ ROMERO, Antonio Manuel; HIGUERAS-MILENA CASTELLANO, Aurora. En prensa: "Ánforas de época romana republicana de procedencia subacuática del Museo de Cádiz". V Congreso Internacional de la SECAH (Alcalá de Henares 2019). Alcalá de Henares.

SÁEZ ROMERO, Antonio Manuel; LÓPEZ JURADO, Reyes. En prensa: "Ceramic Unguentaria from the Bay of Cádiz (Spain) in the 3rd-1st centuries $\mathrm{BC}$. A review of their typological evolution and function". 4th IARPotHP International Conference (Atenas 2019). Atenas.

SÁEZ ROMERO, Antonio Manuel; BELIZÓN ARAGÓN, Ricardo; ZAMORA LÓPEZ, José Ángel. En prensa: "Typological features and capacity standards in transition. The amphorae of Cadiz Bay (southern Iberia) in the 1st millennium BC". Regional Convergences: Mass Production and the Development of Roman and Byzantine Amphora Standardization (Atenas 2017). Atenas.

SANCHEZ, Corinne. 2009: Narbonne à l'époque tardo-républicaine (IIe/Ier s. av. n. è.): Chronologies, commerce et artisanat céramique (Revue Archéologique de Narbonnaise Supplément 38). Association de la Revue Archéologique de Narbonnaise. Montpellier.

SANMARTÍ I GREGO, Enric. 1985: "Las ánforas ro- 
manas del campamento numantino de Peña Redonda (Garray, Soria)". Empúries, 47, pp. 130-161.

SOUSA, Elisa de, 2009: A cerâmica de tipo Kuass no Algarve (Cadernos da UNIARQ 4). Centro de Arqueologia da Universidade de Lisboa. Lisboa

SOUSA, Elisa de. 2017. "Sobre o inicio da romanizaçao do Algarve: 20 anos depois". Archivo Español de Arqueología, 90, pp. 195-218. Doi: 10.3989/aespa.090.017.009.

SOUSA, Elisa de. 2020. "O comercio na costa atlântica portuguesa durante a segunda metade do 1o milénio a.C.". En E. FERRER (ed.): La ruta de las Estrímnides. Navegación y conocimiento del litoral atlántico de Iberia en la Antigüedad, pp. 499-520. Universidad de Alcalá de Henares. Alcalá de Henares.

SOUSA, Elisa de; ARRUDA, Ana Margarida. 2010: "A gaditanizaçao do Algarve". Mainake, 32 (2), pp. 951-974.

SOUSA, Elisa de; ALVES, Catarina; PEREIRA, Teresa Rita. 2016. "O conjunto anfórico da urbanização do Moleão, Lagos (Portugal)”. En R. JÁRREGA y P. BERNI (eds.): Actas del III Congreso Internacional de la Sociedad de Estudios de la Cerámica Antigua (SECAH). Amphorae ex Hispania: paisajes de producción y consumo (Tarragona 2014), pp. 464-478. Instituto Catalán de Arqueología Clásica. Tarragona.
TARRADELL MATEU, Miguel. 1957: “El poblamiento antiguo del valle del río Martín". Tamuda $V$, 2, pp. 247-274.

TARRADELL MATEU, Miguel. 1960: Historia de Marruecos: Marruecos púnico. Publication de la Faculté de Lettres. Rabat.

VANNEY, Jean-René; MENANTEAU, Loïc. 2004: Géographie du golfe ibéro-marocain. Instituto hidrográfico-Casa de Velázquez. Lisboa-Madrid.

VENTURA VILLANUEVA, Ángel; DIOS BORREGO DE LA PAZ, Juan de. 2011: "Notae lapicidinarum lunensium, damnatio memoriae y graffito maldiciente en una inscripción del Teatro Romano de Gades". En D. BERNAL y A. ARÉVALO (eds.): Theatrum Balbi de Gades: actas del Seminario 'El Teatro Romano de Gades, una Mirada al Futuro' (Cádiz 2009), pp. 227-256. Servicio de Publicaciones de la Universidad de Cádiz. Cádiz.

VIEGAS, Catarina. 2011: "Ritmos do povoamento e economia do Algarve Romano: Entre o Mediterrâneo e o Atlântico". O Arqueólogo Português Serie, 5 (1), pp. 15-204. 